\title{
Chronic Traumatic Encephalopathy in Blast-Exposed Military Veterans and a Blast Neurotrauma Mouse Model
}

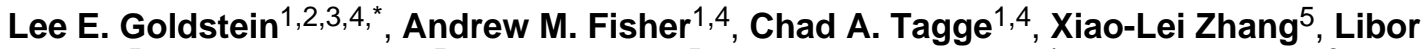 \\ Velisek $^{5}$, John A. Sullivan ${ }^{5}$, Chirag Upreti ${ }^{5}$, Jonathan M. Kracht ${ }^{4}$, Maria Ericsson ${ }^{6}$, Mark W. \\ Wojnarowicz $^{1}$, Cezar J. Goletiani ${ }^{5}$, Giorgi M. Maglakelidze ${ }^{5}$, Noel Casey ${ }^{1,3}$, Juliet A. \\ Moncaster $^{1,3}$, Olga Minaeva ${ }^{1,3,4}$, Robert D. Moir ${ }^{7}$, Christopher J. Nowinski ${ }^{8}$, Robert A. \\ Stern $^{2,8}$, Robert C. Cantu ${ }^{8,9}$, James Geiling ${ }^{10}$, Jan K. Blusztajn ${ }^{2}$, Benjamin L. Wolozin ${ }^{2}$, \\ Tsuneya Ikezu², Thor D. Stein 2,11, Andrew E. Budson 2,11, Neil W. Kowall2,11, David \\ Chargin $^{12}$, Andre Sharon ${ }^{4,12}$, Sudad Saman ${ }^{13}$, Garth F. Hall ${ }^{13}$, William C. Moss ${ }^{14}$, Robin O. \\ Cleveland $^{15}$, Rudolph E. Tanzi ${ }^{7}$, Patric K. Stanton ${ }^{5}$, and Ann C. McKee ${ }^{2,8,11,{ }^{*}}$ \\ ${ }^{1}$ Molecular Aging and Development Laboratory, Boston University School of Medicine, Boston, \\ MA 02118, USA \\ Boston University Alzheimer's Disease Center, Boston, MA 02118, USA \\ ${ }^{3}$ Boston University Photonics Center, Boston University, Boston, MA 02215, USA \\ ${ }^{4}$ College of Engineering, Boston University, Boston, MA 02215, USA \\ ${ }^{5}$ Department of Cell Biology and Anatomy, New York Medical College, Valhalla, NY 10595, USA \\ ${ }^{6}$ Electron Microscope Facility, Harvard Medical School, Boston, MA 02115, USA \\ ${ }^{7}$ Genetics and Aging Research Unit, Massachusetts General Hospital, Charlestown, MA 02129, \\ USA
}

${ }^{8}$ Center for Study of Traumatic Encephalopathy, Boston University School of Medicine, Boston, MA 02118, USA

${ }^{9}$ Department of Neurosurgery, Emerson Hospital, Concord, MA 01742, USA

${ }^{10}$ Department of Medicine, Veterans Affairs Medical Center, White River Junction, VT 05009, USA

${ }^{11}$ Neurology Service, Veterans Affairs Boston Healthcare System, Boston, MA 02130, USA

${ }^{12}$ Fraunhofer Center for Manufacturing Innovation at Boston University, Brookline, MA 02446, USA

${ }^{13}$ Department of Biological Sciences, University of Massachusetts Lowell, Lowell, MA 01854 , USA

${ }^{14}$ Lawrence Livermore National Laboratory, Livermore, CA 94551, USA

${ }^{15}$ Institute of Biomedical Engineering, Department of Engineering Science, University of Oxford, Old Road Campus Research Building, Oxford OX3 7DQ, UK

\section{Abstract}

Blast exposure is associated with traumatic brain injury (TBI), neuropsychiatric symptoms, and long-term cognitive disability. We examined a case series of postmortem brains from U.S. military veterans exposed to blast and/or concussive injury. We found evidence of chronic traumatic encephalopathy (CTE), a tau protein-linked neurodegenerative disease, that was similar to the CTE neuropathology observed in young amateur American football players and a professional 
Table S1. Summary of antibodies used in this study.

Table S2. Murine blast neurotrauma model blast parameters.

Table S3. Shock tube blast compared to equivalent explosive blast.

Fig. S1. Phosphorylated tau axonopathy in a single axon from the brain of a 22-year-old male military veteran with exposure to a

Goldistelo amplovised explosive device blast and persistent blast-related traumatic brain injury symptoms.

Fig. S2. Absence of CTE neuropathology in a representative postmortem human brain from 21-year-old male control subject without

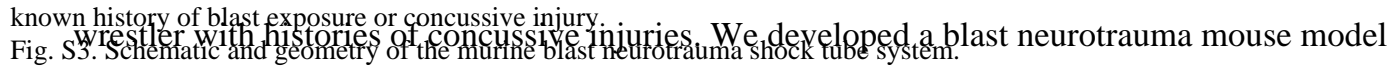

Fig. S4. Reproducibility of shock tube blast static and reflected pressure.

Fig. S5. Peak reflected and static incident pressure as a function of shock tube burst pressure.

Fig. S6. Shock wave velocity (Mach) regression analysis.

Fig. S7. X-T wave diagram demonstrating positional and temporal features of the blast shock wave.

Fig. S8. Unperfused C57BL/6 mouse brain 2 weeks after single shock tube blast exposure.

Fig. S9. Neuropathology in the CA3 field and dentate gyrus in a C57BL/6 mouse brain 2 weeks after exposure to a single shock tube blast.

Fig. S10. Decreased choline acetyltransferase (ChAT) immunoreactivity in the brainstem and neuronal dropout in the cerebellum of C57BL/6 mice 2 weeks after exposure to a single shock tube blast.

Fig. S11. Electron micrographic montage of the hippocampus CA1 field in a C57BL/6 mouse brain 2 weeks after exposure to a single shock tube blast.

Fig. S12. High-magnification electron micrographs of the hippocampus CA1 field in a C57BL/6 mouse brain 2 weeks after singleblast exposure.

Fig. S13. Perivascular ultrastructural pathology in the hippocampus CA1 stratum radiatum in a C57BL/6 mouse brain 2 weeks after exposure to a single shock tube blast.

Fig. S14. Perivascular ultrastructural pathology in the hippocampus CA1 stratum radiatum in a C57BL/6 mouse brain 2 weeks after exposure to a single shock tube blast.

Fig. S15. Perivascular ultrastructural pathology in the hippocampus CA1 stratum radiatum in a C57BL/6 mouse brain 2 weeks after exposure to a single shock tube blast.

Fig. S16. Perivascular ultrastructural pathology in the hippocampus CA1 stratum radiatum in a C57BL/6 mouse brain 2 weeks after exposure to a single shock tube blast.

Fig. S17. Myelin figure in the hippocampus CA1 stratum pyramidale in a C57BL/6 mouse brain 2 weeks after exposure to a single shock tube blast.

Fig. S18. A microglial cell amidst myelinated axons in the hippocampus CA1 stratum alveus in a C57BL/6 mouse brain 2 weeks after exposure to a single shock tube blast.

Fig. S19. Autophagy and mitophagy in the hippocampus CA1 field in a C57BL/6 mouse brain 2 weeks after exposure to a single shock tube blast.

Fig. S20. Degenerating (“dark") pyramidal neurons in the hippocampus CA1 stratum pyramidale in a C57BL/6 mouse brain 2 weeks after exposure to a single shock tube blast.

Fig. S21. Degenerating (dark) pyramidal neurons in the hippocampus CA1 stratum pyramidale in a C57BL/6 mouse brain 2 weeks after exposure to a single shock tube blast.

Fig. S22. Degenerating (dark) pyramidal neurons in the hippocampus CA1 stratum pyramidale in a C57BL/6 mouse brain 2 weeks after exposure to a single shock tube blast.

Fig. S23. Electrode placements for axonal conduction velocity and synaptic plasticity experiments.

Fig. S24. Schaffer collateral-CA1 synaptic input-output relations illustrating the absence of long-term effects of blast exposure on baseline synaptic transmission.

Fig. S25. Blast-induced deficits in cAMP-induced long-term potentiation of synaptic transmission at Schaffer collateral-CA1 synapses are bilateral and persistent.

Fig. S26. Model of blast- and concussion-related TBI and sequelae, including CTE.

Video S1. Mouse head kinematics during exposure to a single shock tube blast.

Competing interests: G.F.H. is a Science Advisory Board member of Immunotrex Biologics Inc. The other authors declare that they have no competing interests. The views expressed in this article are those of authors J.G., A.E.B., N.W.K., and A.C.M. and should not to be construed as official positions of the Department of Veterans Affairs or the U.S. government. Portions of this document were prepared, in part, as an account of work by W.C.M. sponsored by an agency of the U.S. government. Neither the U.S. government nor Lawrence Livermore National Security, LLC, nor any of their employees makes any warranty, expressed or implied, or assumes any legal liability or responsibility for the accuracy, completeness, or usefulness of any information, apparatus, product, or process disclosed, or represents that its use would not infringe privately owned rights. Reference herein to any specific commercial product, process, or service by trade name, trademark, manufacturer, or otherwise does not necessarily constitute or imply its endorsement, recommendation, or favoring by the U.S. government or Lawrence Livermore National Security, LLC. The views and opinions of author W.C.M. expressed herein do not necessarily state or reflect those of the U.S. government or Lawrence Livermore National Security, LLC, and shall not be used for advertising or product endorsement purposes.

Author contributions: L.E.G. designed and interpreted all experiments, analyzed electron microscopy data, designed the shock tube apparatus, provided funding, and wrote the paper; A.M.F., C.A.T., M.W.W., J.M.K., N.C., J.A.M., and O.M. performed and analyzed all shock tube blast mouse experiments and harvested brain tissue; X.-L.Z. designed and performed all electrophysiology experiments; L.V. designed, analyzed, and interpreted all behavioral experiments, provided funding, and wrote the paper; J.A.S. designed and performed electrophysiology and behavioral experiments; C.U. designed and performed electrophysiology experiments; M.E. performed electron microscopy; C.J.G. and G.M.M. performed and analyzed behavioral experiments; R.D.M., S.S., and G.F.H. designed, performed, and interpreted tau biochemical analyses; C.J.N., R.A.S., R.C.C., and J.G. provided and interpreted human clinical data; J.K.B., B.L.W., T.I., A.E.B., and N.W.K. designed animal experiments and edited the paper; T.D.S. analyzed neuropathological data; D.C. and A.S. designed the shock tube blast apparatus; W.C.M. interpreted biophysical data from shock tube experiments and wrote and edited the paper; R.O.C. designed and interpreted all biophysical data from shock tube experiments and wrote and edited the paper; R.E.T. designed and interpreted all experiments and wrote and edited the paper; P.K.S. designed and interpreted electrophysiology and behavioral experiments, provided funding, and wrote the paper; A.C.M. designed and interpreted human clinical and neuropathological data, provided funding, and wrote the paper. 
that recapitulated CTE-linked neuropathology in wild-type C57BL/6 mice 2 weeks after exposure to a single blast. Blast-exposed mice demonstrated phosphorylated tauopathy, myelinated axonopathy, microvasculopathy, chronic neuroinflammation, and neurodegeneration in the absence of macroscopic tissue damage or hemorrhage. Blast exposure induced persistent hippocampal-dependent learning and memory deficits that persisted for at least 1 month and correlated with impaired axonal conduction and defective activity-dependent long-term potentiation of synaptic transmission. Intracerebral pressure recordings demonstrated that shock waves traversed the mouse brain with minimal change and without thoracic contributions. Kinematic analysis revealed blast-induced head oscillation at accelerations sufficient to cause brain injury. Head immobilization during blast exposure prevented blast-induced learning and memory deficits. The contribution of blast wind to injurious head acceleration may be a primary injury mechanism leading to blast-related TBI and CTE. These results identify common pathogenic determinants leading to CTE in blast-exposed military veterans and head-injured athletes and additionally provide mechanistic evidence linking blast exposure to persistent impairments in neurophysiological function, learning, and memory.

\section{INTRODUCTION}

Blast exposure from conventional and improvised explosive devices (IEDs) affects combatants and civilians in conflict regions around the world (1-4). Individuals exposed to explosive blast are at increased risk for traumatic brain injury (TBI) $(2,5-15)$ that is often reported as mild (16 cf., 17). Blast-related TBI represents a neuropsychiatric spectrum disorder that clinically overlaps with chronic traumatic encephalopathy (CTE), a progressive tau protein-linked neurodegenerative disease associated with repetitive concussive injury in athletes (18-21). Neuropathological hallmarks of CTE include widespread cortical foci of perivascular tau pathology, disseminated microgliosis and astrocytosis, myelinated axonopathy, and progressive neurodegeneration. Clinical symptoms of CTE include progressive affective lability, irritability, distractability, executive dysfunction, memory disturbances, suicidal ideation, and in advanced cases, cognitive deficits and dementia.

Blast exposure is a known precipitant of brain injury in animals (22-37) and humans (3842) and has been linked to CTE neuropathology in a single case report by Omalu et al. (43). Despite growing awareness of blast-related TBI, the mechanisms of injury and biological basis underpinning blast neurotrauma and sequelae remain largely unknown and a matter of significant controversy. Given the overlap of clinical signs and symptoms in military personnel with blast-related TBI and athletes with concussion-related CTE, we hypothesized that common biomechanical and pathophysiological determinants may trigger development of CTE neuropathology and sequelae in both trauma settings. Here, we combine clinicopathological correlation analysis and controlled animal modeling studies to test this hypothesis.

\section{RESULTS}

\section{CTE neuropathology in blast-exposed military veterans and athletes with repetitive concussive injury}

We performed comprehensive neuropathological analyses (table S1) of postmortem brains obtained from a case series of military veterans with known blast exposure and/or concussive injury ( $n=4$ males; ages 22 to 45 years; mean, 32.3 years). We compared these neuropathological analyses to those of brains from young amateur American football players and a professional wrestler with histories of repetitive concussive injury ( $n=4$ males; ages 17 to 27 years; mean, 20.8 years) and brains from normal controls of comparable ages without a history of blast exposure, concussive injury, or neurological disease ( $n=4$ males; 
ages 18 to 24 years; mean, 20.5 years). Case 1, a 45-year-old male U.S. military veteran with a single close-range IED blast exposure, experienced a state of disorientation without loss of consciousness that persisted for $\sim 30$ min after blast exposure. He subsequently developed headaches, irritability, difficulty sleeping and concentrating, and depression that continued until his death 2 years later from a ruptured basilar aneurysm. His medical history is notable for a remote history of concussion associated with a motor vehicle accident at age 8 years. Case 2, a 34-year-old male U.S. military veteran without a history of previous concussive injury, sustained two separate IED blast exposures 1 and 6 years before death. Both episodes resulted in loss of consciousness of indeterminate duration. He subsequently developed depression, short-term memory loss, word-finding difficulties, decreased concentration and attention, sleep disturbances, and executive function impairments. His neuropsychiatric symptoms persisted until death from aspiration pneumonia after ingestion of prescription analgesics. Case 3, a 22-year-old male U.S. military veteran with a single close-range IED blast exposure 2 years before death. He did not lose consciousness, but reported headache, dizziness, and fatigue that persisted for 24 hours after the blast. He subsequently developed daily headaches, memory loss, depression, and decreased attention and concentration. In the year before his death, he became increasingly violent and verbally abusive with frequent outbursts of anger and aggression. He was diagnosed with posttraumatic stress disorder (PTSD) 3 months before death from an intracerebral hemorrhage. His past history included 2 years of high school football and multiple concussions from fist fights. Case 4, a 28-year-old male U.S. military veteran with two combat deployments, was diagnosed with PTSD after his first deployment 3 years before death. His history was notable for multiple concussions as a civilian and in combat, but he was never exposed to blast. His first concussion occurred at age 12 after a bicycle accident with temporary loss of consciousness and pre/posttraumatic amnesia. At age 17, he experienced a concussion without loss of consciousness from helmet-to-helmet impact injury during football practice. At age 25 , he sustained a third concussion during military deployment with temporary alteration in mental status without loss of consciousness. Four months later at age 26 , he sustained a fourth concussion with temporary loss of consciousness and posttraumatic amnesia resulting from a motor vehicle-bicycle collision. Afterward, he experienced persistent anxiety, difficulty concentrating, word-finding difficulties, learning and memory impairment, reduced psychomotor speed, and exacerbation of PTSD symptoms. He died from a self-inflicted gunshot wound 2 years after his last concussion. The athlete group included Case 5, a 17-year-old male high school American football player who died from second impact syndrome 2 weeks after sustaining a concussion; Case 6, an 18-year-old high school American football and rugby player with a history of three to four previous concussions, one requiring hospitalization, who died 10 days after his last concussion; Case 7, a 21-year-old male college American football player, who played as a lineman and linebacker but had never been diagnosed with a concussion during his 13 seasons of play beginning at age 9, and who died from suicide; and Case 8, a 27-year-old male professional wrestler who experienced more than 9 concussions during his 10 -year professional wrestling career who died from an overdose of OxyContin. The normal control group included Case 9, an 18-year-old male who died suddenly from a ruptured basilar aneurysm; Case 10, a 19-year-old male who died from a cardiac arrhythmia; Case 11, a 21-year-old male who died from suicide; and Case 12, a 24-year-old male who died from suicide.

Neuropathological analysis of postmortem brains from military veterans with blast exposure and/or concussive injury revealed CTE-linked neuropathology characterized by perivascular foci of tau-immunoreactive neurofibrillary tangles (NFTs) and glial tangles in the inferior frontal, dorsolateral frontal, parietal, and temporal cortices with predilection for sulcal depths (Fig. 1, A, B, E, F, and I to X). NFTs and dystrophic axons immunoreactive for monoclonal antibody CP-13 (Fig. 1, A to I, L, Q, R, and U, and fig. S1) directed against 
phosphorylated tau protein at $\mathrm{Ser}^{202}\left(\mathrm{pS}^{202}\right)$ and $\mathrm{Thr}^{205}\left(\mathrm{pT}^{205}\right)$, monoclonal antibody AT8 (Fig. 1S) directed against phosphorylated tau protein at $\operatorname{Ser}^{202}\left(\mathrm{pS}^{202}\right)$ and $\mathrm{Thr}^{205}\left(\mathrm{pT}^{205}\right)$, and monoclonal antibody Tau-46 (Fig. 1T) directed against phosphorylation-independent tau protein were detected in superficial layers of frontal and parietal cortex and anterior hippocampus. Evidence of axon degeneration, axon retraction bulbs, and axonal dystrophy were observed in the subcortical white matter subjacent to cortical tau pathology (Fig. 1, M and $\mathrm{U}$ to $\mathrm{X}$, and fig. S1). Distorted axons and axon retraction bulbs were prominent in perivascular areas. Large clusters of LN3-immunoreactive activated microglia clusters (Fig. $1, \mathrm{~K}$ and $\mathrm{P}$ ) were observed in subcortical white matter underlying focal tau pathology, but not in unaffected brain regions distant from tau lesions. Neuropathological comparison to brains from young-adult amateur American football players (Fig. 1, C, D, G, and H) with histories of repetitive concussive and subconcussive injury exhibited similar CTE neuropathology marked by perivascular NFTs and glial tangles with sulcal depth prominence in the dorsolateral and inferior frontal cortices. The young-adult athlete brains also revealed evidence of robust astrocytosis and multifocal axonopathy in subcortical white matter. Clusters of activated perivascular microglia were noted in the subcortical U-fibers. Neuropathological findings in the military veterans with blast exposure and/or concussive injury and young-adult athletes with repetitive concussive injury were consistent with our previous CTE case studies $(20,21)$ and could be readily differentiated from neuropathology associated with Alzheimer's disease, frontotemporal dementia, and other age-related neurodegenerative disorders. Control sections omitting primary antibody demonstrated no immunoreactivity. By contrast, none of the brains from the four young-adult normal control subjects demonstrated phosphorylated tau pathology, axonal injury, subcortical astrocytosis, or microglial nodules indicative of CTE or other neurodegenerative disease (fig. S2).

\section{Blast exposure induces traumatic head acceleration in a blast neurotrauma mouse model}

We developed a murine blast neurotrauma model to investigate mechanistic linkage between blast exposure, CTE neuropathology, and neurobehavioral sequelae. Our compressed gas blast tube was designed to accommodate mice (fig. S3) and allowed free movement of the head and cervical spine to model typical conditions associated with military blast exposure (tables S2 and S3 and figs. S3 to S7). Wild-type C57BL/6 male mice (2.5 months) were anesthetized and exposed to a single blast with a static (incident) pressure profile comparable in amplitude, waveform shape, and impulse to detonation of $5.8 \mathrm{~kg}$ of trinitrotoluene (TNT) at a standoff distance of $5.5 \mathrm{~m}$ and in close agreement with ConWep (Conventional Weapons Effects Program) (Fig. 2A and table S3) (44). The model blast is comparable to a common IED fabricated from a $120-\mathrm{mm}$ artillery round and is within the reported range of typical explosives, blast conditions, and standoff distances associated with military blast injury (45).

To investigate intracranial pressure (ICP) dynamics during blast exposure, we inserted a needle hydrophone into the hippocampus of living mice and monitored pressure dynamics during blast exposure. We detected blast wavefront arrival times in the brain that were indistinguishable from corresponding free-field pressure (FFP) measurements in air (Fig. 2B) and in close agreement with ConWep analysis of an equivalent TNT blast (Fig. 2A and table S3). To investigate possible thoracic contributions to blast-induced ICP transients, we evaluated pressure tracings in the hippocampus of intact living mice (Fig. 2B) and compared results to the same measurements obtained in isolated mouse heads severed at the cervical spine (Fig. 2C). Blast-induced pressure amplitudes in the two experimental preparations were comparable to each other and to the corresponding FFP measurements in air, after accounting for the addition of the dynamic pressure on the head. Small differences in the pressure waveforms were within the expected range given frequency-dependent response characteristics of the transducers and differences in the two experimental preparations. We 
did not detect delayed blast-induced ICP transients in either preparation over recording times up to $100 \mathrm{~ms}$. These observations indicate that blast wavefront transmission in the mouse brain is mediated without significant contributions from thoracovascular or hydrodynamic mechanisms.

In our experimental system, the blast shock wave traveling at $\sim 450 \mathrm{~m} / \mathrm{s}$ encountered the left lateral surface of the mouse head first, then traversed the $\sim 11$-mm skull width (46) in 24 $\mu \mathrm{s}$. The pressure differential associated with this traversal has an insignificant effect on skull displacement due to the short time interval. For the remainder of the waveform duration, the static pressures at the lateral surfaces of the skull are virtually identical and the corresponding transient effects are negligible. The air-skull impedance mismatch creates a back-reflected air shock as well as a rapidly moving ( $\geq 1500 \mathrm{~m} / \mathrm{s}$ ) transmitted shock wave, the latter taking a maximum of $\sim 7 \mu$ s to traverse the cranium and cranial contents. Although the reflected and transmitted shock waves are large ( 2.5 times greater than the $77-\mathrm{kPa}$ incident overpressure), the $\sim 7-\mu$ s traversal time of the skull-brain transmitted wave is short enough to allow rapid equilibration across the skull. Thus, the head acts acoustically as a "lumped element" $(47,48)$. The only significant pressure term remaining is the $\sim 19-\mathrm{kPa}$ peak dynamic pressure generated by blast wind. We concluded that an ICP transducer in the brain parenchyma should measure pressure differentials that do not differ by more than 19 $\mathrm{kPa}$ from FFP values, at least beyond the initial $30 \mu \mathrm{s}$ after blast arrival. This analysis was confirmed by experimental measurements (Fig. 2B). Only the initial rise of the blast wave has a short enough time scale to be affected by propagation effects in the head, a prediction confirmed by the longer rise time of the ICP compared to the static FFP waveforms (Fig. 2, $\mathrm{B}$ and $\mathrm{C})$. The remaining waveform components evenly distribute through the brain with amplitude and shape that approximate the static FFP (Fig. 2A).

The blast wave had a measured Mach number of $1.26 \pm 0.04$ (fig. S6), from which the calculated blast wind velocity was $150 \mathrm{~m} / \mathrm{s}$ (336 miles/hour). Kinematic analysis of highspeed videographic records of head movement during blast exposure confirmed rapid oscillating acceleration-deceleration of the head in the horizontal and sagittal planes of motion (Fig. 2, D to G, and video S1). We calculated peak average radial head acceleration of $954 \pm 215 \mathrm{krad} / \mathrm{s}^{2}$ (Fig. $2 \mathrm{G}$ ), corresponding to $100.2 \mathrm{~N}$ exerted on the head during blast exposure. Peak angular and centripetal acceleration were most significant during the positive phase of the blast shock wave. No appreciable head acceleration was detected after $\sim 8 \mathrm{~ms}$.

\section{Single-blast exposure induces CTE-linked neuropathology, ultrastructural pathology, and phosphorylated tau proteinopathy in a blast neurotrauma mouse model}

We hypothesized that blast forces exerted on the skull would result in head accelerationdeceleration oscillation of sufficient intensity to induce persistent brain injury ("bobblehead effect"). To evaluate this hypothesis, we studied brains from mice euthanized 2 weeks after exposure to a single blast or sham blast. Gross examination of postmortem brains from both groups of mice was unremarkable and did not reveal macroscopic evidence of contusion, necrosis, hematoma, hemorrhage, or focal tissue damage (Fig. 3, A to F, and fig. S8). In contrast, brains from blast-exposed mice showed marked neuropathology by immunohistological analysis (Fig. 3, H, J, L, Q, N, S, and T). Blast-exposed brains exhibited robust reactive astrocytosis throughout the cerebral cortex, hippocampus, brainstem, internal capsule, cerebellum, and corticospinal tract (Fig. 3, H and T) that was not observed in brains from sham-blast control mice (Fig. 3, G and O). Brains from blast-exposed mice also exhibited enhanced somatodendritic phosphorylated tau CP-13 immunoreactivity in neurons in the superficial layers of the cerebral cortex (Fig. 3J) that was not observed in the brains of sham-blast control mice (Fig. 3I). The cerebral cortex and CA1 field of the hippocampus in the brains of blast-exposed mice were also notable for clusters of chromatolytic and pyknotic neurons with nuclear and cytoplasmic smudging and beaded, irregularly swollen 
dystrophic axons (Fig. 3, L and Q) that were not observed in the brains of sham-blast control mice (Fig. 3, K and P). Hippocampal CA1 neurons in blast-exposed mice were intensely Tau-46-immunoreactive (Fig. 3, N and S) compared to sham-blast controls (Fig. 3, M and $\mathrm{R})$ and additionally showed evidence of frank neurodegeneration in the hippocampal CA1 and CA3 subfields and dentate gyrus (Fig. 4 and fig. S9). Activated perivascular microglia were observed throughout the brain in blast-exposed mice and were especially notable in the cerebellum (Fig. 3T; compared to control, Fig. 3O). Patchy loss of cerebellar Purkinje cells with empty baskets was also noted in blast-exposed mice (fig. S10H) but not in sham-blast control mice (fig. S10G). Examination of the cervical spinal cords of blast-exposed mice did not reveal evidence of motor neuron dropout or degeneration (fig. S10, A and B). However, blast-exposed mice did show decreased choline acetyltransferase immunoreactivity in motor neurons in the cervical cord (fig. S10D) and cranial nerve XII (fig. S10F) when compared to sham-blast controls (fig. S10, C and E), suggesting loss of central cholinergic inputs.

Ultrastructural pathology was observed in electron micrographs of neurons, axons, and capillaries in the hippocampi of blast-exposed mice but not in sham-blast control mice (Fig. 4 and figs. S11 to S22). Examination of semithick sections of hippocampus CA1 and CA3 regions and dentate gyrus in brains from blast-exposed mice revealed clusters of chromatolytic and pyknotic neurons throughout the stratum pyramidale and a marked paucity of dendritic profiles in the stratum radiatum (Fig. 4H and fig. S9, B and C) that was not evident in the brains of sham-blast control mice (Fig. 4A and fig. S9A). Blast-related ultrastructural microvascular pathology was notable for the presence of hydropic perivascular astrocytic end-feet (Fig. 4, I and J, and figs. S11, S13 to S16, S19C, and S20). Pathologically swollen, edematous, and often highly vacuolated astrocytic end-feet were observed in association with dysmorphic capillaries marked by pathologically thickened, tortuous basal lamina and abnormal endothelial cells with irregularly shaped nuclei (Fig. 4L and figs. S11 to S16). Perivascular processes in the hippocampi of blast-exposed mice often contained inclusion bodies, lipofuscin granules, myelin figures, and autophagic vacuoles (Fig. 4, I, L, and N, and figs. S11, S12, S14, and S17 to S19). Pericytes (Fig. 4, I and L, and figs. S11, S12, S14, and S16), microglial cells (fig. S18), dystrophic myelinated nerve fibers (Fig. 4K and figs. S15 to S17 and S19A), and "dark neurons" (Fig. 4M and figs. S20 to S22) with electron-dense cytoplasm and irregularly shaped nuclei were frequently observed in proximity to these abnormal capillaries in blast-exposed mice. By contrast, the brains of sham-blast control mice exhibited normal hippocampal cytoarchitecture without evidence of ultrastructural neuropathology (Fig. 4, A to G).

To confirm the presence of phosphorylated tau proteinopathy in the brains of blast-exposed mice, we performed immunoblot analysis of tissue homogenates prepared from brains harvested from mice 2 weeks after single-blast or sham-blast exposure (Fig. 5). Immunoblot analysis revealed a significant blast-related elevation of phosphorylated tau protein epitopes $\mathrm{pT}^{181}$ and $\mathrm{pS}^{202}$ detected by monoclonal antibody CP-13 (Fig. 5, A, B, and G) and $\mathrm{pT}^{205}$ detected by monoclonal antibody AT270 (Fig. 5, C, D, and I) that are associated with early neurodegenerative tau misprocessing. Blast-related tau phosphorylation was also detected when quantitated as a ratio of phosphorylated tau protein to total tau protein (Fig. 5, E, F, H, and $\mathrm{J}$ ). In mice exposed to sham blast, all three of the major native murine tau isoforms (4R2N, 4R0N, and 4R1N) were evident (Fig. 5E). By contrast, immunoblots of brain homogenates prepared from mice exposed to a single blast revealed a tau protein isoform distribution pattern that was dominated by a single band corresponding to the intermediatesized native tau isoform (4R1N; Fig. 5F). Phosphorylated tauopathy (Fig. 5, B and D) and tau isoform distribution abnormalities (Fig. 5F) were detected bilaterally, a finding consistent with blast-related CTE neuropathology and electrophysiological deficits. Blastinduced brain tau proteinopathy was confirmed by enzyme-linked immunosorbent assay 
(ELISA) analysis of tau protein phosphorylated at $\mathrm{pSer}^{199}$ (single blast, $40 \pm 2 \mathrm{ng} / \mathrm{ml}$; sham blast, $31 \pm 2 \mathrm{ng} /$ liter; $P=0.027$, two-tailed Student's $t$ test).

\section{Single-blast exposure persistently impairs axonal conduction and long-term potentiation of activity-dependent synaptic transmission in the hippocampus}

We investigated the possibility that blast-related histopathological and ultrastructural abnormalities would be reflected in equally persistent functional impairments in hippocampal neurophysiology. Analysis of Schaffer collateral-evoked synaptic field potential input-output relations (fig. S23B) did not reveal an effect of blast exposure on baseline synaptic transmission at either 2 weeks or 1 month after blast exposure (fig. S24). However, axonal conduction velocity of CA1 pyramidal cell compound action potentials in the stratum alveus (fig. 23A) was significantly slowed 2 weeks after blast exposure, an effect that persisted for at least 1 month [Fig. 6 , A and B; $P<0.05$, repeated-measures multifactorial analysis of variance (ANOVA)].

Next, we examined the effect of blast exposure on stimulus- and cyclic adenosine monophosphate (cAMP)-evoked long-term potentiation (LTP) of synaptic strength at Schaffer collateral-CA1 synapses (fig. S23B), candidate mechanisms of memory storage. We found marked impairments of stimulus-evoked LTP in mouse slices prepared 2 weeks and 1 month after blast exposure (Fig. 6C; $P<0.05$, repeated-measures multifactorial ANOVA). When the 2-week and 1-month blast-exposed cohorts were examined independently, we found that the magnitude of posttetanic potentiation (PTP) immediately after application of theta-burst stimulation (TBS) was significantly less at the 2-week time point (Fig. 6E; $P<0.05$, repeated-measures multifactorial ANOVA). Although PTP recovered by 1 month after blast, the magnitude of LTP 1 hour after tetanus was significantly reduced at both postblast time points (Fig. 6E; $P<0.05$, repeated-measures multifactorial ANOVA). These results indicate that exposure to single blast impaired longterm activity-dependent synaptic plasticity for at least 1 month after blast exposure in our model. Next, we examined cAMP-dependent LTP of Schaffer collateral-CA1 field excitatory postsynaptic potentials (fEPSPs) induced by 15 -min bath application of the adenylate cyclase activator forskolin $(50 \mu \mathrm{M})$ plus the type II phosphodiesterase inhibitor rolipram $(10 \mu \mathrm{M})$. In contrast to control slices, cAMP-LTP was profoundly attenuated 30 to 60 min after drug washout in hippocampal slices prepared from both left and right hemispheres of mice 2 weeks and 1 month after blast exposure (Fig. 6D and fig. S25, A and B; $P<0.05$, repeated-measures multifactorial ANOVA). As with stimulus-evoked LTP, cAMP-LTP was equally impaired at both 2 weeks and 1 month after blast exposure, demonstrating the long-term nature of blast effects on both activity-dependent and chemically evoked synaptic plasticity (Fig. 6F; $P<0.05$, repeated-measures multifactorial ANOVA).

\section{Single-blast exposure induces long-term behavioral deficits that are prevented by head immobilization during blast exposure}

We did not detect significant differences between single-blast and sham-blast mice in total distance, mean velocity, or central zone entries in open-field behavior testing (Fig. 7, A to C), indicating that blast exposure did not impair gross neurological functioning with respect to locomotion, exploratory activity, and thigmotaxis (an indicator of murine anxiety assessed by movement close to the wall of the experimental apparatus). In contrast, when we tested acquisition and long-term retention of hippocampal-dependent spatial learning and memory in the Barnes maze (Fig. 7, D to F), we observed that blast-exposed mice exhibited significantly longer escape latencies (Fig. 7D; $P<0.05$, two-way ANOVA) and poorer memory retrieval 24 hours after the final training session (Fig. 7E; $P<0.05$, Student's $t$ test) 
compared to sham-blast control mice. These findings are consistent with persistent blastrelated hippocampal dysfunction.

The results of kinematic analysis (Fig. 2, D to G) suggested that blast-induced head acceleration was a likely pathogenic mechanism by which blast exposure leads to TBI and neurobehavioral sequelae. To test this hypothesis, we compared hippocampal-dependent learning acquisition and memory retention in mice with and without head immobilization during single-blast exposure and in sham-blast control mice. Head immobilization during blast exposure eliminated blast-related impairments in hippocampal-dependent learning acquisition (Fig. 7D; $P>0.20$, repeated-measures ANOVA with post hoc Scheffe test compared to sham-blast controls) and restored blast-related memory retention deficits to normal levels (Fig. 7E; $P>0.20$, one-way ANOVA with post hoc Scheffe test), supporting the conclusion that head acceleration is necessary for behavioral learning impairments.

\section{DISCUSSION}

We analyzed a case series of postmortem human brains from U.S. military veterans with blast exposure and/or concussive injury and compared them to brains from young-adult athletes with histories of concussive injury and from normal controls of comparable ages without histories of blast exposure, concussive injury, or neurological disease. We uncovered evidence of CTE-linked tau neuropathology, including multifocal perivascular foci of neurofibrillary and glial tangles immunoreactive for phosphorylation-independent (Tau-46) and phosphorylation-dependent (CP-13) tau epitopes (20,21), in the brains of blast-exposed and/or concussive-injured veterans. This blast-associated CTE-linked tau neuropathology was indistinguishable from the tau neuropathology, neuroinflammation, and neurodegeneration observed in the brains of young-adult athletes with histories of repeat concussive injury. Examination of brains from wild-type C57BL/6 mice 2 weeks after exposure to a single controlled blast also revealed histopathological, ultrastructural, and biochemical evidence of CTE-linked neuropathology, including tau protein-linked immunoreactivity, persistent perivascular pathology, cortical and hippocampal neurodegeneration, myelinated axonopathy, chronic neuroinflammation with widespread astrocytosis and microgliosis, and phosphorylated tau proteinopathy. Overall, our findings of persistent CTE-linked neuropathology in the brains of military veterans with blast exposure and/or concussive injury and young athletes with repeat concussive injury suggest that TBI induced by different insults under different conditions can trigger common pathogenic mechanisms leading to similar neuropathology and sequelae. Notably, within this small controlled case series, the effects of blast exposure, concussive injury, and mixed trauma (blast exposure and concussive injury) were indistinguishable.

Experimental results from our murine blast neurotrauma model provide evidence linking blast exposure with development of CTE-like tau neuropathology. Moreover, this blastrelated neuropathology was associated with persistent neurophysiological and cognitive deficits that recapitulate clinical signs and symptoms reported in military veterans with blast-related TBI $(2,7,9-15)$ and concussive-injured athletes diagnosed with CTE $(20,21)$. It is notable that exposure to a single blast in our mouse model was sufficient to induce early CTE-like neuropathology, slowed axonal conduction velocity, and defective stimulus- and cAMP-dependent LTP of synaptic transmission. Notably, these blast-related neurophysiological abnormalities were contemporaneous with somatodendritic alterations in hippocampal and cortical total tau and phosphorylated tau neuropathology and biochemistry, microvascular ultrastructural pathology, and impairment in hippocampal-dependent learning acquisition and memory retention. 
Although blast-exposed C57BL/6 mice recapitulated key features of human CTE neuropathology, including cellular accumulation of phosphorylated tau protein and pretangle tau protein neuropathology, it is notable that mature NFTs were not detected in the cortex or hippocampus of blast-exposed mice. This apparent discordance with human CTE neuropathology may be explained by the early time points chosen for evaluation in our mouse studies or, alternatively, as a forme fruste resulting from resistance of wild-type murine tau protein to form neurotoxic aggregates in vivo. However, our results demonstrate blast-related immunohistochemical and biochemical abnormalities in tau hyperphosphorylation at the 2-week time point after single-blast exposure. Studies of tripletransgenic mice expressing human tau protein and human amyloid- $\beta$ peptide have shown that controlled cortical impact injury leads to rapid accumulation of hyperphosphorylated tau within 24 hours after experimental injury $(49,50)$. These findings suggest that genotypic determinants may be critical factors that modulate temporal and phenotypic expression of TBI and late-emerging sequelae, including CTE.

ICP dynamics recorded during blast exposure revealed blast-induced pressure transients in the hippocampus that were coincident with and comparable in amplitude, waveform, and impulse to FFP measurements outside the cranium. This finding is consistent with the head acting as a lumped element for which the blast-induced external pressure differential equilibrates within $\sim 100 \mu \mathrm{s}$. Measured blast pressure amplitudes in the brain were on the order of $100 \mathrm{kPa}(\sim 1 \mathrm{bar})$, a magnitude equivalent to water pressure at a depth of $\sim 10 \mathrm{~m}$. Although it is possible that high-frequency components $(>100 \mathrm{kHz})$ could lead to localized focusing due to reverberation and constructive interference, the pressure amplitudes we measured were far below tissue damage thresholds. Tissue damage associated with clinical ultrasound requires negative acoustic pressures in excess of $1 \mathrm{MPa}(51)$ that lead to excitation of cavitation bubbles. Thresholds for positive pressures are not well characterized but are likely to exceed $40 \mathrm{MPa}$ because positive pressures commonly used in clinical shock wave lithotripsy are not associated with significant, if any, tissue damage (52). Thresholds for tissue damage from underwater sonar require $\sim 100 \mathrm{kPa}$ (53) and result from many cycles of bubble growth and collapse over tens of seconds of continuous wave excitation. Tissue damage in this setting is due to the negative pressure rather than exposure to a single compression pulse. These considerations indicate that direct tissue damage resulting from transmission of the blast shock wave through the brain is unlikely. Our results indicate that ICP transients closely approximate FFP measurements in air $(27,54,55)$. Moreover, blast wavefront transmission was identical when measured in the brain of intact living mice or isolated mouse heads severed at the cervical spine, suggesting that neither thoracic-mediated mechanisms nor vascular hemodynamic effects contributed significantly to ICP transients during blast exposure. Together, our findings point to the substantial inertial forces and oscillating acceleration-deceleration cycles imposed on the head by blast wind (bobblehead effect) as the primary biomechanical mechanism by which blast exposure initiates acute closed-head brain injury and sequelae, including CTE (fig. S26).

Here, we describe CTE-linked neuropathology in the brains of military veterans with blast exposure and/or concussive injury, young-adult athletes with repetitive concussive injury, and mice subjected to a single blast. These observations are consistent with a common injury mechanism involving oscillating head acceleration-deceleration cycles (bobblehead effect; fig. S26) that lead to pathogenic shearing strain imposed on the cranial contents (56-60). Our observation that head immobilization during blast exposure prevented hippocampaldependent learning and memory deficits in blast-exposed mice provides additional support for this injury mechanism and postulated relationship to persistent neurobehavioral sequelae. Recent studies have identified local strain amplification near micromechanical heterogeneities in the brain, including sulci, blood vessels, and axons as possible contributory factors leading to blast-related brain injury $(48,61,62)$. Simulation studies 
indicate that pressure gradients in the brain of an unhelmeted head resulting from military blast exposure may be sufficiently large to generate damaging intracranial forces, even in the absence of direct impact trauma to the head (63). Ultrastructural analysis indicates that blast exposure in our experimental model was associated with persistent microvascular pathology, including abnormal blood-brain barrier (BBB) cytoarchitecture. Blast-related ultrastructural pathology may be associated with pericyte degeneration (64) and/or microvascular compression secondary to astrocytic end-feet swelling (65), thereby leading to BBB compromise, local hypoxia, chronic neuroinflammation, and neurodegeneration. These postulated mechanisms are consistent with recent experimental studies (66-68), finite element head modeling analyses $(60,69)$, and the results in this report. Further studies are needed to differentiate the relative contributions of these and possibly other pathogenic mechanisms.

The significance of the neurophysiological abnormalities in blast-exposed wild-type C57BL/ 6 mice is substantial. First, although blast exposure did not produce detectable long-term dysfunction in basal synaptic transmission, exposure to a single sublethal blast was sufficient to induce profound and persistent impairment of both activity-and cAMPdependent LTP in hippocampal CA1 pyramidal neurons, candidate cellular mechanisms of long-term memory processing. The fact that both forms of LTP require dendritic protein synthesis $(70,71)$ and gene transcription (72) indicate that blast exposure may induce longlasting damage to cellular signal transduction downstream of synaptic glutamate release. Mechanisms that may be altered by blast exposure include $N$-methyl-D-aspartate glutamate receptor activation, intracellular second messenger systems, gene expression, protein synthesis, and posttranslational modification. Our results also indicate that blast exposure can induce persistent axonal conduction defects that further impair cognitive processing and are consistent with recent findings from human studies $(14,15)$. These effects may be mediated by diffuse axonal injury, Wallerian degeneration, and/or differential susceptibility of larger neurons to structural or functional axotomy. Damage to these and other brain structures, systems, and mechanisms may contribute to abnormalities in neurochemical homeostasis, cerebral metabolism, and neurophysiological functions associated with blastrelated TBI (73). Our results suggest that blast exposure may hold comparable or even greater pathogenic potential than repetitive head injury associated with contact athletics (7476).

Limitations of the human neuropathology reported here include the small number of available cases, the time interval between trauma and postmortem examination, potential contributions of confounding comorbidities and risk factors, and inherent limitations of neuropathological analysis to establish mechanistic causality. Clinicopathological correlation may be further complicated by genetic contributions [for example, APOE (apolipoprotein E) genotype (77)], history of previous head trauma, innate inflammatory responsivity, neuropsychiatric co-morbidity, age and gender, and other factors with potential to modulate susceptibility and pathological expression of blast-related neurotrauma and sequelae. Furthermore, emerging evidence indicates that PTSD may represent an important overlapping comorbidity with potential to synergistically affect both the incidence and the severity of blast TBI and military deployment-related cognitive dysfunction $(2,7,78-80)$. Limitations of our animal experiments include use of adult male C57BL/6 wild-type mice subjected to a single-blast exposure with post-exposure evaluation at time points only up to 1 month. Interpretation and generalizability of our animal experiments are further constrained by inter-species differences, including the significantly greater deformability of the murine skull, the relative instability of the murine cervical spine, and differential force loading on the head and neck in mice and humans. 
Our results provide compelling evidence linking blast exposure to long-lasting brain injury.

Specifically, our study raises concern that blast exposure may increase risk for later development of CTE and associated neurobehavioral sequelae. Indeed, the severity, persistence, and possible progression of the neuropathological abnormalities and neurophysiological deficits observed in our study indicate that blast exposure is a potent insult with enduring pathogenic potential and functional significance. The availability of a neuropathologically validated murine model with correspondence to human CTE is expected to open new avenues for investigation of mechanisms, biomarkers, and risk factors relevant to blast-related brain injury and facilitate development of urgently needed diagnostics, therapeutics, and prophylactic measures for blast neurotrauma and its aftermath.

\section{MATERIALS AND METHODS}

\section{Human subjects}

The brain and spinal cord of 12 human subjects (male military veterans, ages 22 to 45 years, mean 32.3 years, with histories of explosive blast and/or concussive injury 1 to 6 years before death, $n=4$; male athletes with histories of repetitive concussive injury, including 3 amateur American football players and a professional wrestler, ages 17 to 27 years, mean 20.8 years, $n=4$; male normal controls, ages 18 to 24 years, mean 20.5 years, without known blast exposure, trauma history, or neurological disease, $n=4$ ) were procured through the Boston University Alzheimer's Disease Center and Center for the Study of Traumatic Encephalopathy at Boston University School of Medicine. Blast exposure, trauma history, and neurological status at the time of death were determined through review of medical records and interviews with next of kin. Ethical permission to conduct this investigation was approved by Institutional Review Board at Boston University School of Medicine. The study conforms to institutional regulatory guidelines and principles of human subject protection in the Declaration of Helsinki.

\section{Animal subjects}

Adult wild-type C57BL/6 male mice (Charles River Laboratories) were group-housed at the Laboratory Animal Science Center, Boston University School of Medicine. All animal experiments used 2.5-month-old mice with 8 to 10 mice per group. Animal housing and experimental use were conducted in accordance with Association for Assessment and Accreditation of Laboratory Animal Care guidelines, in compliance with the Animal Welfare Act and other federal statutes and regulations relating to animals and experiments involving animals, and adherence to principles in the National Research Council Guide for the Care and Use of Laboratory Animals. All studies were approved by Institutional Animal Care and Use Committees at Boston University School of Medicine and New York Medical College.

\section{Histopathological and electron microscopic analyses}

Postmortem human brain and spinal cord were received as fresh tissue and as fixed tissue in formalin after processing by medical examiners. Neuropathological analysis followed established protocols at the Boston University Alzheimer's Disease Center and included comprehensive examination for all neurodegenerative conditions (81). Paraffin-embedded sections from at least 15 brain regions were stained with Luxol fast blue, hematoxylin and eosin, and Bielschowsky silver stain. Mice were euthanized by $\mathrm{CO}_{2}$ asphyxiation and transcardially perfused with phosphate-buffered saline (PBS). Whole brains were prefixed in $10 \%$ neutral buffered formalin, block-sectioned into 2 -mm coronal slabs, postfixed in $4 \%$ paraformaldehyde, paraffin-embedded, and serially sectioned at $10 \mu \mathrm{m}$. A battery of primary detection antibodies (table S1) was used for immunohistopathological analyses. Ultrastructural studies were conducted on fixed brain specimens embedded in Epon, sectioned at 
$60 \mathrm{~nm}$, stained with uranyl acetate or lead citrate, and examined with a Tecnai-G2 Spirit

BioTWIN electron microscope with an AMT 2K CCD camera.

\section{Murine blast neurotrauma model system}

A compressed gas-driven shock tube (fig. S3) was developed in collaboration with the Fraunhofer Center for Manufacturing Innovation at Boston University (Brookline, MA) and installed at the Neurotrauma Laboratory, Boston University School of Medicine. This instrument was used to deliver highly reproducible blast waves (Fig. 2A, figs. S3 to S7, and tables S2 and S3). Adult wild-type C57BL/6 male mice (2.5 months) were anesthetized with ketamine $(75 \mathrm{mg} / \mathrm{kg}$, intraperitoneally), xylazine ( $4.3 \mathrm{mg} / \mathrm{kg}$, intraperitoneally), and buprenorphine $(0.2 \mathrm{mg} / \mathrm{kg}$, subcutaneously) and secured in the prone position in a thoracicprotective restraint system inside the shock tube (fig. S3). The head and neck were free to allow flexion, extension, and rotation of the cervical spine in the horizontal and sagittal planes of motion to model conditions relevant to military blast exposure. Maximum burst pressure compatible with $100 \%$ survival and no gross motor abnormalities was ascertained empirically (table S2). Experimental blast parameters (incident static pressure, $77 \pm 2 \mathrm{kPag}$; blast overpressure rise time, $38 \pm 3 \mu \mathrm{s}$; compressive phase duration, $4.8 \pm 0.1 \mathrm{~ms}$; shock wave velocity, $1.26 \pm 0.04 \mathrm{Mach}$; calculated blast wind velocity, $150 \mathrm{~m} / \mathrm{s}=336 \mathrm{miles} / \mathrm{hour}$; table S2) closely approximate explosive blast produced by detonation of $5.8 \mathrm{~kg}$ of TNT measured at a standoff distance of $5.5 \mathrm{~m}$ [ConWep analysis (44); table S3]. This blast exposure is within the range of typical IED detonations and standoff distances associated with military blast injury (45). Anesthetized mice were exposed to a single blast or sham blast, removed from the apparatus, monitored until recovery of gross locomotor function, and then transferred to their home cage.

\section{Static and reflected FFP measurements}

Assessment of static and reflected FFP was assessed by two piezoelectric pressure sensors (model HM102A15, PCB Piezotronics) placed in the shock tube at the same axial distance relative to the head of the animal subjects. A static pressure (side-on) sensor was flushedmounted inside the shock tube. A second transducer was positioned with the detector facing into the shock tube in a reflected pressure (face-on) orientation. Pressure signals were processed with a PCB signal conditioner (model 482C05, PCB Piezotronics) and recorded at a frequency of $5 \mathrm{MHz}$ with a digital oscilloscope (640Zi WaveRunner, LeCroy). Voltages were converted to pressure with calibration data provided by the manufacturer and processed with 2-kHz low-pass filtering.

\section{ICP measurements}

ICP measurements were conducted with a broad-bandwidth piezoelectric needle hydrophone (NP10-3, DAPCO Industries) with a 0.6-mm-diameter element sheathed in a stainless steel hypodermic needle. Pressure sensitivity was flat to within $\pm 3 \mathrm{~dB}$ for frequencies ranging from $1 \mathrm{~Hz}$ to $170 \mathrm{kHz}$. The needle hydrophone was inserted into the hippocampus at -3.00 $\mathrm{mm}$ caudal to the bregma suture, $+3.50 \mathrm{~mm}$ lateral to the sagittal suture, and $+2.00 \mathrm{~mm}$ ventral to the skull surface. For ICP measurements, the head was immobilized to prevent displacement of the pressure sensor. Piezoelectric voltage signals were recorded by a digital oscilloscope (640Zi WaveRunner, LeCroy) and converted to pressure units with calibration data supplied by the manufacturer and processed with $20-\mathrm{kHz}$ low-pass filtering. Postacquisition processing was performed with Matlab 2009 (MathWorks).

\section{High-speed videographic kinematic analysis}

High-speed videography was conducted with a FASTCAM SA5 camera (Photron USA Inc.; courtesy of Tech Imaging) operated at $10-\mu$ s frame capture rate. Videographic records were 
reassembled with open-source ImageJ software and processed in Matlab (MathWorks). Angular position and motion of the head were assessed by tracking a reflective paint mark on the snout, calculated by assuming a central pivot point between the scapulae (fig. S3B), and processed with 500-Hz low-pass filtering (Fig. 2, D to G, fig. S3B, and video S1).

\section{Hippocampal electrophysiology}

Mice were decapitated under deep isoflurane anesthesia, and the brains were quickly removed, hemisected, and sectioned with a Leica model VT $1200 \mathrm{~S}$ vibratome at $350 \mu \mathrm{m}$. Slices were fixed to a stage with cyanoacrylate adhesive and immersed in oxygenated artificial cerebrospinal fluid (126 mM NaCl, $3 \mathrm{mM} \mathrm{KCl}, 1.25 \mathrm{mM} \mathrm{NaH}_{2} \mathrm{PO}_{4}, 1.3 \mathrm{mM}$ $\mathrm{MgCl}_{2}, 2.5 \mathrm{mM} \mathrm{CaCl}_{2}, 26 \mathrm{mM} \mathrm{NaHCO}_{3}, 10 \mathrm{mM}$ glucose, saturated with $95 \% \mathrm{O}_{2}$ and $5 \%$ $\mathrm{CO}_{2}$ ) at $32^{\circ} \mathrm{C}$. Experimental drugs were bath applied in the perfusate at a rate of $3 \mathrm{ml} / \mathrm{min}$. Axonal conduction velocity was assessed with a recording electrode placed in CA1 stratum alveus. Schaffer collateral-CA1 synaptic transmission and plasticity were assessed with a recording electrode in the $\mathrm{CA} 1$ stratum radiatum.

\section{Hippocampal-dependent learning and memory}

Open-field testing (Med-Associates) was used to assess gross locomotor function, exploratory activity, and thigmotaxis. Hippocampal-dependent learning acquisition and memory retention were evaluated in the Barnes maze (82). Spatial learning was assisted by visual cues in the environment that remained constant across test sessions. Movement was tracked and recorded electronically (Stoelting). Latency to find the escape box, trajectory velocity to the escape box, and total trajectory distance were assessed and recorded daily in four sessions conducted over 4 days. Memory retrieval was electronically assessed by recording the number of nose pokes in blank holes as a percentage of total nose pokes recorded 24 hours after completion of the learning protocol.

\section{Quantitative assessment of phosphorylated and total tau protein}

Quantitative immunoblot analysis was conducted with left and right hemisected brains obtained from PBS-perfused mice 2 weeks after exposure to a single blast ( $n=6$ mice) or sham blast ( $n=6$ mice). Snap-frozen hemisected brain specimens were thawed, resuspended in $0.7 \mathrm{ml}$ of protease-phosphatase inhibitor buffer, and homogenized as previously described (83). Protein concentrations were normalized and equal sample volumes were subjected to standard polyacrylamide gel electrophoresis in duplicate. Immunoblot detection used monoclonal antibody AT270 (Innogenetics) directed against tau protein phosphorylated at $\mathrm{Thr}^{181}\left(\mathrm{pT}^{181}\right.$ ), monoclonal antibody CP-13 (P. Davies, Albert Einstein College of Medicine) directed against tau protein phosphorylated at $\mathrm{Ser}^{202}\left(\mathrm{pS}^{202}\right)$ and $\mathrm{Thr}^{205}$, or monoclonal antibody Tau 5 (L. Binder, Northwestern University Medical School) directed against phosphorylation-independent tau protein. Triplicate densitometry measurements were analyzed with open-source ImageJ software. A commercial ELISA kit was used to quantitate murine-specific tau protein phosphorylated at $\operatorname{Ser}^{199}$ (Invitrogen). Frozen brain samples were homogenized in eight volumes of $5 \mathrm{M}$ guanidine- $\mathrm{HCl}$ and $50 \mathrm{mM}$ tris $(\mathrm{pH} \mathrm{8})$ followed by five passes in a glass Teflon homogenizer. Homogenates were mixed for 3 hours, diluted into PBS containing protease inhibitors, and centrifuged for $20 \mathrm{~min}$ at $16,000 \mathrm{~g}$. Supernatants were diluted and assayed in quadruplicate according to the manufacturer's instructions.

\section{Statistical analyses}

Comparisons of axonal conduction velocity and LTP magnitude were conducted with repeated-measures multifactorial ANOVA with Bonferroni-Dunn post hoc correction. 
Longitudinal neurobehavioral data were analyzed by repeated-measures ANOVA. Memory retrieval was evaluated by ANOVA. Statistical significance was preset at $P<0.05$.

\section{Supplementary Material}

Refer to Web version on PubMed Central for supplementary material.

\section{Acknowledgments}

We gratefully acknowledge the use of resources and facilities at the Edith Nourse Rogers Memorial Veterans Hospital (Bedford, MA) and expert assistance provided by A. Peters (Department of Anatomy and Neurobiology, Boston University School of Medicine) for electron microscopy consultation, L. McHale and M. Nowinski for tireless logistical assistance and administrative support, K. Cormier and C. A. Kubilus for histotechnology assistance, and P. Davies (Albert Einstein College of Medicine) and J. Bertelsen (Signet/Covance) for antibodies We gratefully acknowledge the individuals and families whose participation and contributions made this work possible. This work is dedicated to U.S. military servicemen and women, past and present, for their sacrifices, dedication, and service to our country.

Funding: Supported by National Institute of General Medical Sciences grant GM75986 (L.E.G.); National Center for Research Resources grant S10RR026599 (L.E.G.); NSF grants 0901760 and 0821304 (L.E.G.); Cure Alzheimer's Fund (L.E.G., R.D.M., and R.E.T.), Office of the Dean, Boston University School of Medicine; Office of the Provost, Boston University (L.E.G.); Boston University Photonics Center Neurophotonics Pilot Project Grant (L.E.G.); Cooperative Agreement W911NG-06-2-0040 between the U.S. Army and Boston University Photonics Center (L.E.G.); Department of Veterans Affairs (A.C.M.); Translational Research Center for TBI and Stress Disorders (TRACTS) VA Rehabilitation Research and Development Traumatic Brain Injury Center of Excellence (B6796-C; A.C.M., L.E.G.); National Institute of Aging Center grant P30AG13846 (N.W.K.), Supplement 0572063345-5 (N.W.K.), and Pilot Project Grant (N.C.); NIH/National Institute of Biomedical Imaging and Bioengineering T32 Training Grant Award 5T32EB006359 and NIH/National Institute of Neurological Disorders and Stroke Pre-Doctoral Fellowship Research grant F31NS077796 (C.A.T.); National Institute of Diabetes and Digestive and Kidney Diseases grant P01DK043881 (R.O. C.); National Institute of Neurological Diseases and Stroke grants NS044421 (P.K.S.), NS072966 (L.V.), and R01NS078337 (R.A.S.); Department of Defense grant W81XWH (P.K.S.); Migraine Research Foundation (P.K.S.); March of Dimes Foundation grant 6FY08591 (L.V.); National Operating Committee on Standards for Athletic Equipment (A.C.M.); an unrestricted gift from the National Football League (A.C.M.); and Department of Energy Contract DE-AC52-07NA27344 to the Lawrence Livermore National Laboratory (W.C.M.).

\section{REFERENCES AND NOTES}

1. TRITON Report. Allen-Vanguard Threat Solutions; Shrivenham, UK: 2011.

2. Hoge CW, McGurk D, Thomas JL, Cox AL, Engel CC, Castro CA. Mild traumatic brain injury in U.S. Soldiers returning from Iraq. N Engl J Med. 2008; 358:453-463. [PubMed: 18234750]

3. Wolf SJ, Bebarta VS, Bonnett CJ, Pons PT, Cantrill SV. Blast injuries. Lancet. 2009; 374:405-415. [PubMed: 19631372]

4. [accessed 24 February 2012] Independent Panel on the Safety and Security of United Nations Personnel in Iraq. http://www.un.org/News/dh/iraq/safety-security-un-personnel-iraq.pdf

5. Taber KH, Warden DL, Hurley RA. Blast-related traumatic brain injury: What is known? J Neuropsychiatry Clin Neurosci. 2006; 18:141-145. [PubMed: 16720789]

6. Murray CK, Reynolds JC, Schroeder JM, Harrison MB, Evans OM, Hospenthal DR. Spectrum of care provided at an echelon II Medical Unit during Operation Iraqi Freedom. Mil Med. 2005; 170:516-520. [PubMed: 16001604]

7. Tanielian, TL.; Jaycox, LH. Invisible Wounds of War: Psychological and Cognitive Injuries, Their Consequences, and Services to Assist Recovery. RAND Corporation; Santa Monica, CA: 2008.

8. Terrio H, Brenner LA, Ivins BJ, Cho JM, Helmick K, Schwab K, Scally K, Bretthauer R, Warden D. Traumatic brain injury screening: Preliminary findings in a US Army Brigade Combat Team. J Head Trauma Rehabil. 2009; 24:14-23. [PubMed: 19158592]

9. Ling G, Bandak F, Armonda R, Grant G, Ecklund J. Explosive blast neurotrauma. J Neurotrauma. 2009; 26:815-825. [PubMed: 19397423] 
10. Benzinger TL, Brody D, Cardin S, Curley KC, Mintun MA, Mun SK, Wong KH, Wrathall JR. Blast-related brain injury: Imaging for clinical and research applications: Report of the $2008 \mathrm{St}$. Louis workshop. J Neurotrauma. 2009; 26:2127-2144. [PubMed: 19508154]

11. Vasterling JJ, Verfaellie M, Sullivan KD. Mild traumatic brain injury and posttraumatic stress disorder in returning veterans: Perspectives from cognitive neuroscience. Clin Psychol Rev. 2009; 29:674-684. [PubMed: 19744760]

12. Hicks RR, Fertig SJ, Desrocher RE, Koroshetz WJ, Pancrazio JJ. Neurological effects of blast injury. J Trauma. 2010; 68:1257-1263. [PubMed: 20453776]

13. Brenner LA, Ivins BJ, Schwab K, Warden D, Nelson LA, Jaffee M, Terrio H. Traumatic brain injury, posttraumatic stress disorder, and postconcussive symptom reporting among troops returning from Iraq. J Head Trauma Rehabil. 2010; 25:307-312. [PubMed: 20042982]

14. Peskind ER, Petrie EC, Cross DJ, Pagulayan K, McCraw K, Hoff D, Hart K, Yu CE, Raskind MA, Cook DG, Minoshima S. Cerebrocerebellar hypometabolism associated with repetitive blast exposure mild traumatic brain injury in 12 Iraq war veterans with persistent post-concussive symptoms. Neuroimage. 2011; 54(Suppl 1):S76-S82. [PubMed: 20385245]

15. Mac Donald CL, Johnson AM, Cooper D, Nelson EC, Werner NJ, Shimony JS, Snyder AZ, Raichle ME, Witherow JR, Fang R, Flaherty SF, Brody DL. Detection of blast-related traumatic brain injury in U.S. military personnel. N Engl J Med. 2011; 364:2091-2100. [PubMed: 21631321]

16. Department of Veterans Affairs and Department of Defense. [accessed 7 March 2012] Clinical practice guideline: Management of concussion/mild traumatic brain injury. http:// www.healthquality.va.gov/management_of_concussion_mtbi.asp

17. Menon DK, Schwab K, Wright DW, Maas AI. Demographics and Clinical Assessment Working Group of the International and Interagency Initiative toward Common Data Elements for Research on Traumatic Brain Injury and Psychological Health, Position statement: Definition of traumatic brain injury. Arch Phys Med Rehabil. 2010; 91:1637-1640. [PubMed: 21044706]

18. Miller H. Mental after-effects of head injury. Proc R Soc Med. 1966; 59:257-261. [PubMed: 5909768]

19. Omalu BI, DeKosky ST, Minster RL, Kamboh MI, Hamilton RL, Wecht CH. Chronic traumatic encephalopathy in a National Football League player. Neurosurgery. 2005; 57:128-134. [PubMed: 15987548]

20. McKee AC, Cantu RC, Nowinski CJ, Hedley-Whyte ET, Gavett BE, Budson AE, Santini VE, Lee HS, Kubilus CA, Stern RA. Chronic traumatic encephalopathy in athletes: Progressive tauopathy after repetitive head injury. J Neuropathol Exp Neurol. 2009; 68:709-735. [PubMed: 19535999]

21. McKee AC, Gavett BE, Stern RA, Nowinski CJ, Cantu RC, Kowall NW, Perl DP, Hedley-Whyte ET, Price B, Sullivan C, Morin P, Lee HS, Kubilus CA, Daneshvar DH, Wulff M, Budson AE. TDP-43 proteinopathy and motor neuron disease in chronic traumatic encephalopathy. $\mathbf{J}$ Neuropathol Exp Neurol. 2010; 69:918-929. [PubMed: 20720505]

22. Celander H, Clemedson CJ, Ericsson UA, Hultman HI. The use of a compressed air operated shock tube for physiological blast research. Acta Physiol Scand. 1955; 33:6-13. [PubMed: 14349723]

23. Richmond DR, Damon EG, Bowen IG, Fletcher ER, White CS. Air-blast studies with eight species of mammals. Techn Progr Rep DASA 1854. Fission Prod Inhal Proj. 1967:1-44.

24. Phillips, Y.; Richmond, D. Textbook of Military Medicine. Part I. Warfare, Weapons, and the Casualty. Zatchuck, R.; Jenkins, D.; Bellamy, R.; Quick, C., editors. Vol. 5. TMM Publications; Washington, DC: 1990. p. 221-240.

25. Kaur C, Singh J, Lim MK, Ng BL, Yap EP, Ling EA. The response of neurons and microglia to blast injury in the rat brain. Neuropathol Appl Neurobiol. 1995; 21:369-377. [PubMed: 8632831]

26. Elsayed NM. Toxicology of blast overpressure. Toxicology. 1997; 121:1-15. [PubMed: 9217311]

27. Säljö A, Arrhén F, Bolouri H, Mayorga M, Hamberger A. Neuropathology and pressure in the pig brain resulting from low-impulse noise exposure. J Neurotrauma. 2008; 25:1397-1406. [PubMed: 19146459]

28. Knudsen S, Øen EO. Blast-induced neurotrauma in whales. Neurosci Res. 2003; 46:377-386. [PubMed: 12804799] 
29. Long JB, Bentley TL, Wessner KA, Cerone C, Sweeney S, Bauman RA. Blast overpressure in rats: Recreating a battlefield injury in the laboratory. J Neurotrauma. 2009; 26:827-840. [PubMed: 19397422]

30. Bauman RA, Ling G, Tong L, Januszkiewicz A, Agoston D, Delanerolle N, Kim Y, Ritzel D, Bell R, Ecklund J, Armonda R, Bandak F, Parks S. An introductory characterization of a combatcasualty-care relevant swine model of closed head injury resulting from exposure to explosive blast. J Neurotrauma. 2009; 26:841-860. [PubMed: 19215189]

31. Svetlov SI, Prima V, Kirk DR, Gutierrez H, Curley KC, Hayes RL, Wang KK. Morphologic and biochemical characterization of brain injury in a model of controlled blast overpressure exposure. $\mathrm{J}$ Trauma. 2010; 69:795-804. [PubMed: 20215974]

32. Cernak I, Merkle AC, Koliatsos VE, Bilik JM, Luong QT, Mahota TM, Xu L, Slack N, Windle D, Ahmed FA. The pathobiology of blast injuries and blast-induced neurotrauma as identified using a new experimental model of injury in mice. Neurobiol Dis. 2011; 41:538-551. [PubMed: 21074615]

33. Koliatsos VE, Cernak I, Xu L, Song Y, Savonenko A, Crain BJ, Eberhart CG, Frangakis CE, Melnikova T, Kim H, Lee D. A mouse model of blast injury to brain: Initial pathological, neuropathological, and behavioral characterization. J Neuropathol Exp Neurol. 2011; 70:399-416. [PubMed: 21487304]

34. Chavko M, Watanabe T, Adeeb S, Lankasky J, Ahlers ST, McCarron RM. Relationship between orientation to a blast and pressure wave propagation inside the rat brain. J Neurosci Methods. 2011; 195:61-66. [PubMed: 21129403]

35. Nakagawa A, Manley GT, Gean AD, Ohtani K, Armonda R, Tsukamoto A, Yamamoto H, Takayama K, Tominaga T. Mechanisms of primary blast-induced traumatic brain injury: Insights from shock-wave research. J Neurotrauma. 2011; 28:1101-1119. [PubMed: 21332411]

36. Risling M, Plantman S, Angeria M, Rostami E, Bellander BM, Kirkegaard M, Arborelius U, Davidsson J. Mechanisms of blast induced brain injuries, experimental studies in rats. Neuroimage. 2011; 54(Suppl 1):S89-S97. [PubMed: 20493951]

37. Lu J, Ng KC, Ling G, Wu J, Poon DJ, Kan EM, Tan MH, Wu YJ, Li P, Moochhala S, Yap E, Lee LK, Teo M, Yeh IB, Sergio DM, Chua F, Kumar SD, Ling EA. Effect of blast exposure on the brain structure and cognition in Macaca fascicularis. J Neurotrauma. 2012; 29:1434-1454. [PubMed: 21639720]

38. Mott FW. The effects of high explosives upon the central nervous system. Lancet. 1916; 187:331338. 441-449, 545-553.Neuroses, War; Shock, Shell. Frowde, Hodder \& Stoughton; London: 1919.

39. Fulton JF. Blast and concussion in the present war. N Engl J Med. 1942; 226:1-8.

40. Denny-Brown D. The sequelae of war head injuries. N Engl J Med. 1942; 227:771-780.

41. Cohen H, Biskind GR. Pathologic aspects of atmospheric blast injuries in man. Arch Pathol. 1946; 42:12-34.

42. Elder GA, Mitsis EM, Ahlers ST, Cristian A. Blast-induced mild traumatic brain injury. Psychiatr Clin North Am. 2010; 33:757-781. [PubMed: 21093677]

43. Omalu B, Hammers JL, Bailes J, Hamilton RL, Kamboh MI, Webster G, Fitzsimmons RP. Chronic traumatic encephalopathy in an Iraqi war veteran with posttraumatic stress disorder who committed suicide. Neurosurg Focus. 2011; 31:E3. [PubMed: 22044102]

44. Hyde, DW. CONWEP 2.1.0.8, Conventional Weapons Effects Program. United States Army Corps of Engineers; Vicksburg, MS: 2004.

45. Nelson TJ, Clark T, Stedje-Larsen ET, Lewis CT, Grueskin JM, Echols EL, Wall DB, Felger EA, Bohman HR. Close proximity blast injury patterns from improvised explosive devices in Iraq: A report of 18 cases. J Trauma. 2008; 65:212-217. [PubMed: 17514045]

46. The Jackson Laboratory. [accessed 22 February 2012] MPD: Jaxpheno1. Mouse Phenome Database. http://phenome.jax.org

47. Blackstock, DT. Fundamentals of Physical Acoustics. Wiley; New York: 2000. p. 146-150.

48. Cloots RJ, van Dommelen JA, Nyberg T, Kleiven S, Geers MG. Micromechanics of diffuse axonal injury: Influence of axonal orientation and anisotropy. Biomech Model Mechanobiol. 2011; 10:413-422. [PubMed: 20635116] 
49. Tran HT, Laferla FM, Holtzman DM, Brody DL. Controlled cortical impact traumatic brain injury in $3 \times \mathrm{Tg}-\mathrm{AD}$ mice causes acute intra-axonal amyloid- $\beta$ accumulation and independently accelerates the development of tau abnormalities. J Neurosci. 2011; 31:9513-9525. [PubMed: 21715616]

50. Shitaka Y, Tran HT, Bennett RE, Sanchez L, Levy MA, Dikranian K, Brody DL. Repetitive closed-skull traumatic brain injury in mice causes persistent multifocal axonal injury and microglial reactivity. J Neuropathol Exp Neurol. 2011; 70:551-567. [PubMed: 21666502]

51. Hynynen K, McDannold N, Martin H, Jolesz FA, Vykhodtseva N. The threshold for brain damage in rabbits induced by bursts of ultrasound in the presence of an ultrasound contrast agent (Optison). Ultrasound Med Biol. 2003; 29:473-481. [PubMed: 12706199]

52. Evan AP, Willis LR, McAteer JA, Bailey MR, Connors BA, Shao Y, Lingeman JE, Williams JC Jr, Fineberg NS, Crum LA. Kidney damage and renal functional changes are minimized by waveform control that suppresses cavitation in shock wave lithotripsy. J Urol. 2002; 168:15561562. [PubMed: 12352457]

53. Crum LA, Mao Y. Acoustically enhanced bubble growth at low frequencies and its implications for human diver and marine mammal safety. J Acoust Soc Am. 1996; 99:2898-2907. [PubMed: 8642113]

54. Clemedson CJ, Pettersson H. Propagation of a high explosive air shock wave through different parts of an animal body. Am J Physiol. 1956; 184:119-126. [PubMed: 13283101]

55. Chavko M, Koller WA, Prusaczyk WK, McCarron RM. Measurement of blast wave by a miniature fiber optic pressure transducer in the rat brain. J Neurosci Methods. 2007; 159:277-281. [PubMed: 16949675]

56. Holbourn AHS. Mechanics of head injuries. Lancet. 1943; 242:438-441.

57. Strich SJ. Shearing of nerve fibres as a cause of brain damage due to head injury: A pathological study of twenty cases. Lancet. 1961; 2:443-448.

58. Gennarelli, TA.; Thibault, LE.; Ommaya, AK. Biomechanics of Impact Injury and Injury Tolerances of the Head-Neck Complex. Backaitis, SH., editor. Society of Automotive Engineers Inc; Warrendale, PA: 1993.

59. Krave U, Höjer S, Hansson HA. Transient, powerful pressures are generated in the brain by a rotational acceleration impulse to the head. Eur J Neurosci. 2005; 21:2876-2882. [PubMed: 15926935]

60. Zhang J, Yoganandan N, Pintar FA, Gennarelli TA. Role of translational and rotational accelerations on brain strain in lateral head impact. Biomed Sci Instrum. 2006; 42:501-506. [PubMed: 16817658]

61. Povlishock JT. Pathobiology of traumatically induced axonal injury in animals and man. Ann Emerg Med. 1993; 22:980-986. [PubMed: 8503536]

62. Cloots RJ, Gervaise HM, van Dommelen JA, Geers MG. Biomechanics of traumatic brain injury: Influences of the morphologic heterogeneities of the cerebral cortex. Ann Biomed Eng. 2008; 36:1203-1215. [PubMed: 18465248]

63. Moss WC, King MJ, Blackman EG. Skull flexure from blast waves: A mechanism for brain injury with implications for helmet design. Phys Rev Lett. 2009; 103:108702. [PubMed: 19792349]

64. Bell RD, Winkler EA, Sagare AP, Singh I, LaRue B, Deane R, Zlokovic BV. Pericytes control key neurovascular functions and neuronal phenotype in the adult brain and during brain aging. Neuron. 2010; 68:409-427. [PubMed: 21040844]

65. Ito U, Hakamata Y, Kawakami E, Oyanagi K. Temporary cerebral ischemia results in swollen astrocytic end-feet that compress microvessels and lead to delayed focal cortical infarction. J Cereb Blood Flow Metab. 2011; 31:328-338. [PubMed: 20588315]

66. Fijalkowski RJ, Stemper BD, Pintar FA, Yoganandan N, Crowe MJ, Gennarelli TA. New rat model for diffuse brain injury using coronal plane angular acceleration. J Neurotrauma. 2007; 24:1387-1398. [PubMed: 17711400]

67. Alford PW, Dabiri BE, Goss JA, Hemphill MA, Brigham MD, Parker KK. Blast-induced phenotypic switching in cerebral vasospasm. Proc Natl Acad Sci USA. 2011; 108:12705-12710. [PubMed: 21765001] 
68. Browne KD, Chen XH, Meaney DF, Smith DH. Mild traumatic brain injury and diffuse axonal injury in swine. J Neurotrauma. 2011; 28:1747-1755. [PubMed: 21740133]

69. Zhu F, Mao H, Dal Cengio Leonardi A, Wagner C, Chou C, Jin X, Bir C, Vandevord P, Yang KH, King AI. Development of an FE model of the rat head subjected to air shock loading. Stapp Car Crash J. 2010; 54:211-225. [PubMed: 21512910]

70. Kelleher RJ III, Govindarajan A, Tonegawa S. Translational regulatory mechanisms in persistent forms of synaptic plasticity. Neuron. 2004; 44:59-73. [PubMed: 15450160]

71. Tsokas P, Grace EA, Chan P, Ma T, Sealfon SC, Iyengar R, Landau EM, Blitzer RD. Local protein synthesis mediates a rapid increase in dendritic elongation factor 1A after induction of late longterm potentiation. J Neurosci. 2005; 25:5833-5843. [PubMed: 15958750]

72. Bramham CR. Local protein synthesis, actin dynamics, and LTP consolidation. Curr Opin Neurobiol. 2008; 18:524-531. [PubMed: 18834940]

73. Barkhoudarian G, Hovda DA, Giza CC. The molecular pathophysiology of concussive brain injury. Clin Sports Med. 2011; 30:33-48. [PubMed: 21074080]

74. Pellman EJ, Viano DC, Tucker AM, Casson IR, Waeckerle JF. Concussion in professional football: Reconstruction of game impacts and injuries. Neurosurgery. 2003; 53:799-812. [PubMed: 14519212]

75. Guskiewicz KM, Mihalik JP, Shankar V, Marshall SW, Crowell DH, Oliaro SM, Ciocca MF, Hooker DN. Measurement of head impacts in collegiate football players: Relationship between head impact biomechanics and acute clinical outcome after concussion. Neurosurgery. 2007; 61:1244-1252. [PubMed: 18162904]

76. Broglio SP, Schnebel B, Sosnoff JJ, Shin S, Fend X, He X, Zimmerman J. Biomechanical properties of concussions in high school football. Med Sci Sports Exerc. 2010; 42:2064-2071. [PubMed: 20351593]

77. Terrell TR, Bostick RM, Abramson R, Xie D, Barfield W, Cantu R, Stanek M, Ewing T. APOE, APOE promoter, and Tau genotypes and risk for concussion in college athletes. Clin J Sport Med. 2008; 18:10-17. [PubMed: 18185033]

78. Vasterling JJ, Proctor SP, Amoroso P, Kane R, Heeren T, White RF. Neuropsychological outcomes of army personnel following deployment to the Iraq war. JAMA. 2006; 296:519-529. [PubMed: 16882958]

79. Stein MB, McAllister TW. Exploring the convergence of posttraumatic stress disorder and mild traumatic brain injury. Am J Psychiatry. 2009; 166:768-776. [PubMed: 19448186]

80. Vasterling JJ, Proctor SP, Friedman MJ, Hoge CW, Heeren T, King LA, King DW. PTSD symptom increases in Iraq-deployed soldiers: Comparison with nondeployed soldiers and associations with baseline symptoms, deployment experiences, and post-deployment stress. J Trauma Stress. 2010; 23:41-51. [PubMed: 20135698]

81. Vonsattel JP, Aizawa H, Ge P, DiFiglia M, McKee AC, MacDonald M, Gusella JF, Landwehrmeyer GB, Bird ED, Richardson EP Jr, Hedley-Whyte ET. An improved approach to prepare human brains for research. J Neuropathol Exp Neurol. 1995; 54:42-56. [PubMed: 7815079]

82. Barnes CA. Memory deficits associated with senescence: A neurophysiological and behavioral study in the rat. J Comp Physiol Psychol. 1979; 93:74-104. [PubMed: 221551]

83. Saman S, Kim W, Raya M, Visnick Y, Miro S, Saman S, Jackson B, McKee AC, Alvarez VE, Lee NC, Hall GF. Exosome-associated tau is secreted in tauopathy models and is selectively phosphorylated in cerebrospinal fluid in early Alzheimer disease. J Biol Chem. 2012; 287:38423849. [PubMed: 22057275]

84. Formby SA, Wharton RK. Blast characteristics and TNT equivalence values for some commercial explosives detonated at ground level. J Hazard Mater. 1996; 50:183-198.

85. Cullis IG. Blast waves and how they interact with structures. J R Army Med Corps. 2001; 147:1626. [PubMed: 11307674]

86. Champion HR, Holcomb JB, Young LA. Injuries from explosions: Physics, biophysics, pathology, and required research focus. J Trauma. 2009; 66:1468-1477. [PubMed: 19430256] 

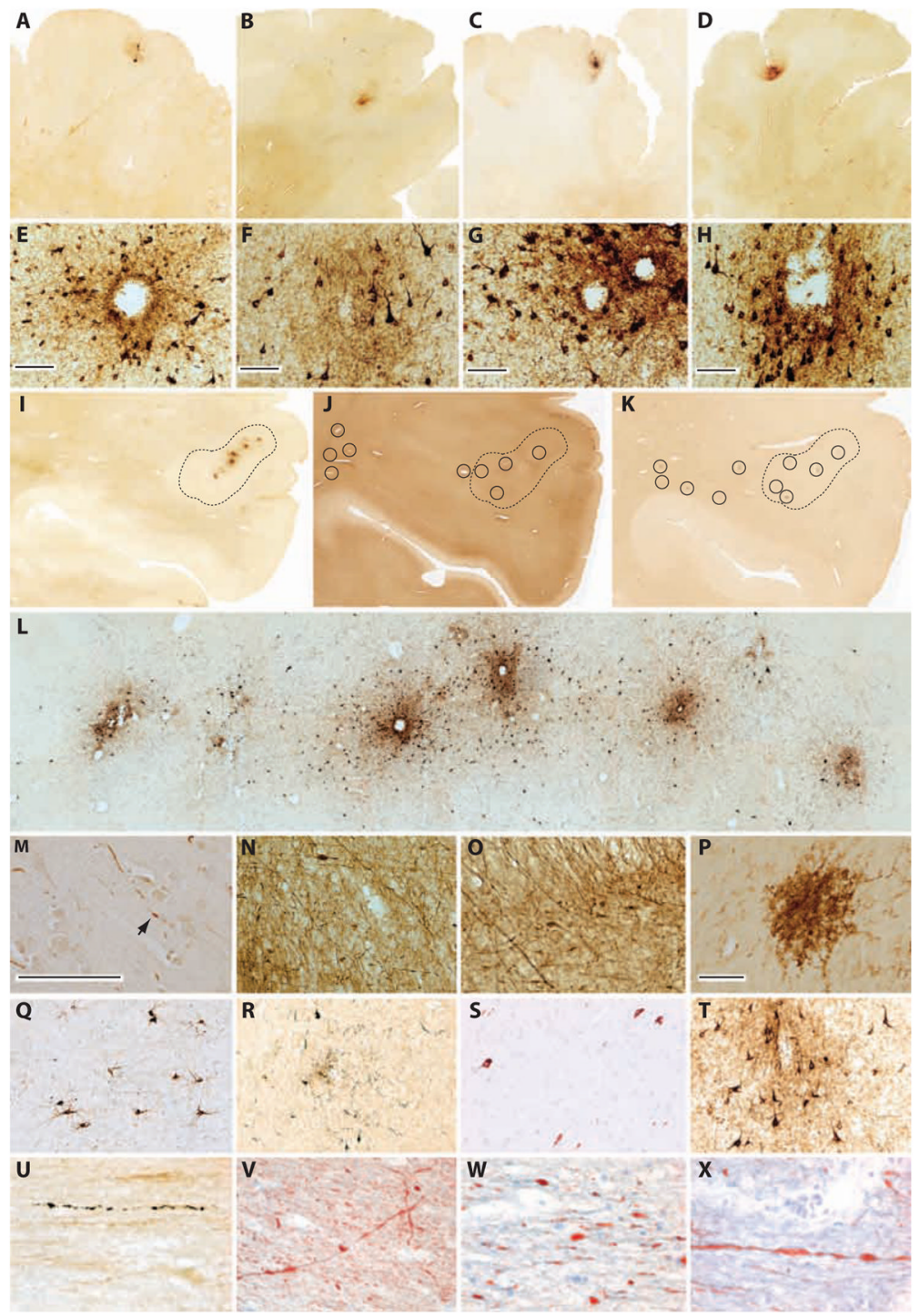

Fig. 1.

CTE neuropathology in postmortem brains from military veterans with blast exposure and/or concussive injury and young athletes with repetitive concussive injury. (A and $\mathbf{E})$ Case 1, phosphorylated tau (CP-13) neuropathology with perivascular neurofibrillary degeneration in the frontal cortex of a 45-year-old male military veteran with a history of single closerange blast exposure 2 years before death and a remote history of concussion. Whole-mount section. Scale bar (E), $100 \mu \mathrm{m}$. (B and F) Case 2, phosphorylated tau (CP-13)

neuropathology with perivascular neurofibrillary degeneration in the frontal cortex of a 34year-old male military veteran with history of two blast exposures 1 and 6 years before death and without a history of concussion. Whole-mount section. Scale bar (F), $100 \mu \mathrm{m}$. (C and G) Case 6, phosphorylated tau (CP-13) neuropathology with perivascular neurofibrillary degeneration in the frontal cortex of an 18-year-old male amateur American football player with a history of repetitive concussive injury. Whole-mount section. Scale bar (G), $100 \mu \mathrm{m}$. (D and $\mathbf{H})$ Case 7, phosphorylated tau (CP-13) neuropathology with perivascular neurofibrillary degeneration in the frontal cortex of a 21-year-old male amateur American football player with a history of repetitive subconcussive injury. Whole-mount section. Scale bar $(\mathrm{H}), 100 \mu \mathrm{m}$. (I) Case 1, phosphorylated tau (CP-13) immunostaining in the parietal 
cortex revealed a string of perivascular foci demonstrating intense immunoreactivity (areas enclosed by hash lines). Whole-mount section. (J) Case 1, phosphorylated neurofilament (SMI-34) immunostaining in adjacent parietal cortex section demonstrating colocalization of multifocal axonal swellings and axonal retraction bulbs surrounding small blood vessels (black circles) relative to perivascular tau foci (areas enclosed by hash lines). Whole-mount section. (K) Case 1, human leukocyte antigen-DR (HLA-DR) (LN3) immunostaining in adjacent parietal cortex section demonstrating colocalization of microglial clusters (black circles) relative to perivascular tau foci (areas enclosed by hash lines). Whole-mount section. (L) Case 1, high-magnification micrograph of phosphorylated tau (CP-13) immunostaining in the parietal cortex demonstrating string of perivascular phosphorylated tau foci. Whole-mount section. (M) Case 1, phosphorylated tau (PHF-1, brown) and phosphorylated neurofilament (SMI-34, red) double immunostaining in parietal cortex demonstrating axonal swellings and a retraction bulb (arrow) in continuity with phosphorylated tau neuritic abnormalities. Whole-mount section. Scale bar, $100 \mu \mathrm{m}$. (N) Case 1, phosphorylated neurofilament (SMI-34) immunostaining showing diffuse axonal degeneration and multifocal irregular axonal swellings in subcortical white matter subjacent to cortical tau pathology. Whole-mount section. (O) Case 1, phosphorylated neurofilament (SMI-34) immunostaining demonstrating perivascular axonal pathology and axonal retraction bulbs near a small cortical blood vessel. Whole-mount section. (P) Case 1, activated microglia (LN3) immunostaining showing a large microglial nodule in the subcortical white matter subjacent to cortical tau pathology. LN3 immunostaining was not observed in brain areas devoid of tau pathology. Whole-mount section. Scale bar, $100 \mu \mathrm{m}$. (Q) Case 2, phosphorylated tau (CP-13) immunostaining showing diffuse neuronal tau pathology (pre-tangles) in the hippocampal CA1 field. Whole-mount section. (R) Case 2, phosphorylated tau (CP-13) pathology in temporal cortex. Whole-mount section. (S) Case 1, phosphorylated tau (AT8) immunostaining showing diffuse neuronal tau pathology (pretangles) in the hippocampal CA1 field. Whole-mount section. (T) Case 1, phosphorylationindependent total tau (Tau-46) immunostaining in the frontal cortex. Whole-mount section. (U) Case 3, phosphorylated tau (CP-13) immunostained axonal varicosities in the external capsule of a 22-year-old male military veteran with a history of a single close-range IED blast exposure and remote history of concussions. Whole-mount section. ( $\mathbf{V}$ to $\mathbf{X}$ ) Case 3, SMI-34 immunostained axonal varicosities and retraction bulbs in the thalamic fasiculus and external capsule. Whole-mount sections. 
A

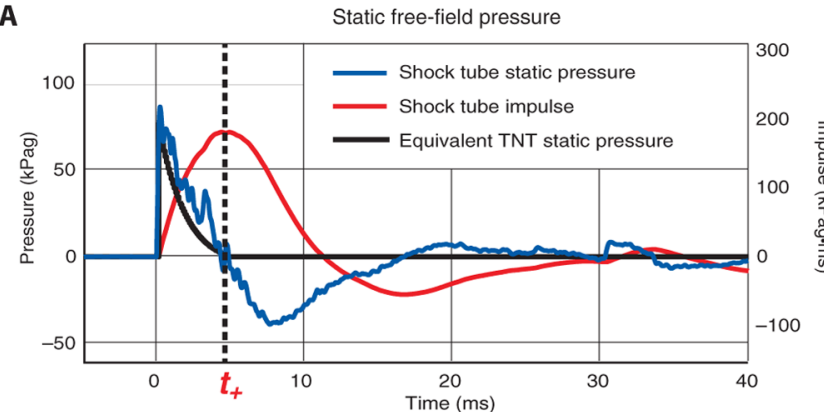

B

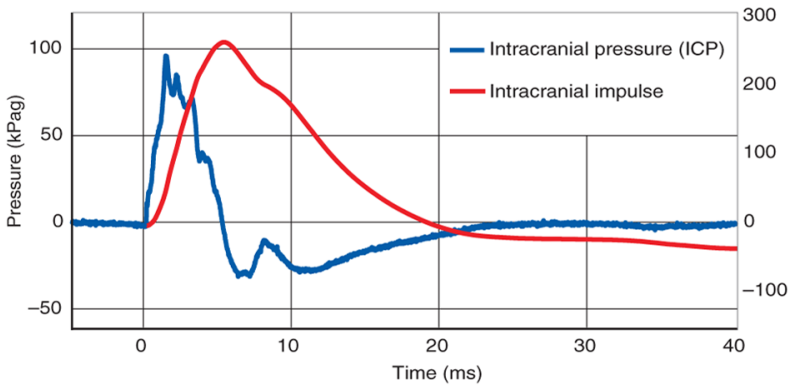

C

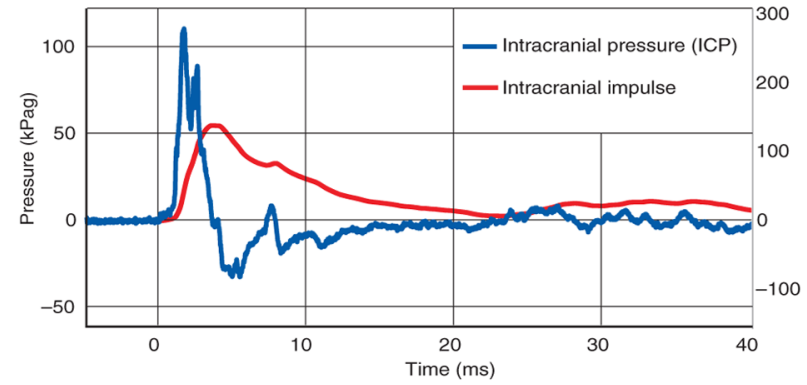

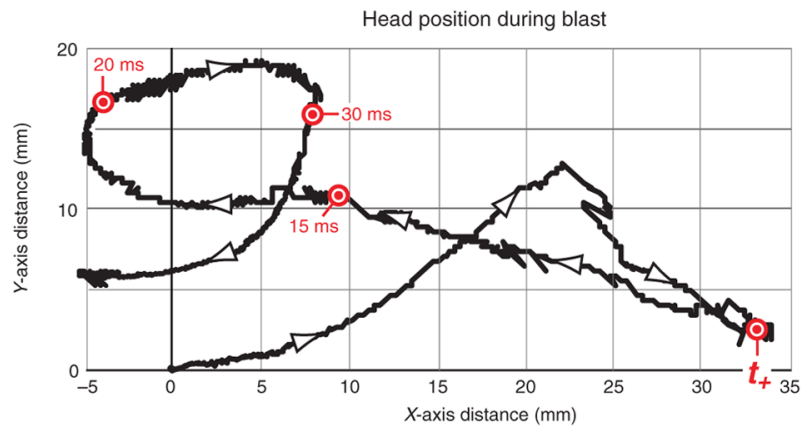

E

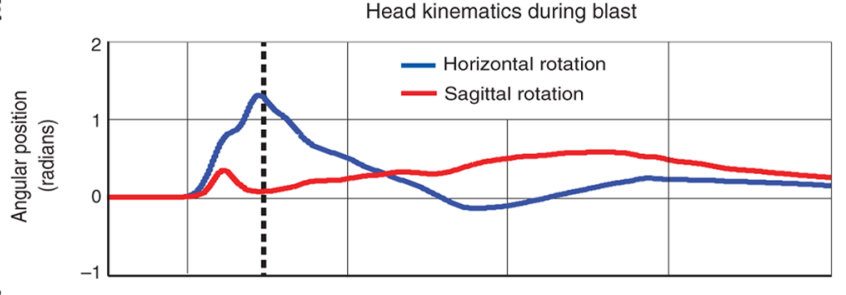

$\mathbf{F}$

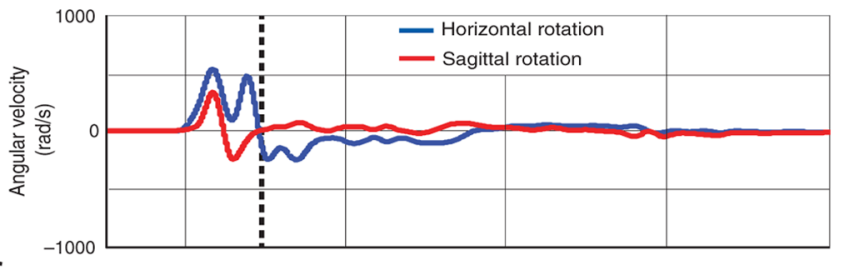

G

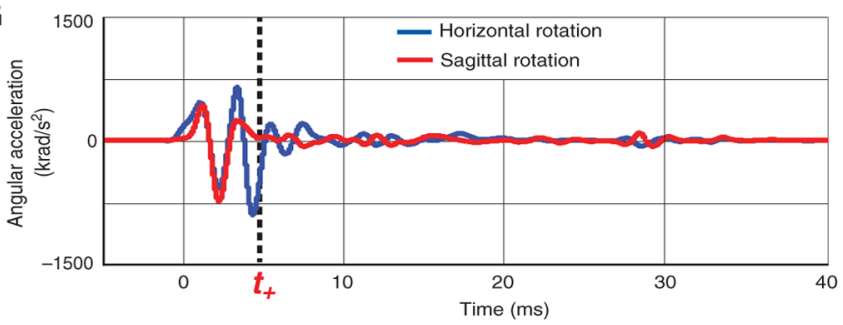

Fig. 2.

Free-field pressure (FFP) and intracranial pressure (ICP) dynamics and head kinematics during single-blast exposure in a blast neurotrauma mouse model. (A) Measured incident static blast pressure (blue line) and blast impulse (red line) are compared to equivalent explosive blast waveform expected from $5.8 \mathrm{~kg}$ of TNT at a standoff distance of $5.5 \mathrm{~m}$ (black line) calculated according to software analysis using ConWep (44). The positive phase terminates at $4.8 \mathrm{~ms}\left(t_{+}=4.8 \mathrm{~ms}\right.$; black hash line). Blast characteristics and waveform structure are comparable to a typical IED fabricated from a $120-\mathrm{mm}$ artillery round $(4.53 \mathrm{~kg}$ of TNT equivalent charge weight). The measured blast waveform and equivalent TNT blast waveform are in close agreement with a leading shock wavefront followed by a smooth decay. Note that ConWep presents an idealized blast resulting from an above-ground spherical charge and does not model negative-phase pressure transients or modulating factors commonly encountered in military blast scenarios. Reflecting surfaces, bounding structures (for example, crew compartments in armored vehicles, rooms within buildings, walled streets, and alleyways), local geometry, device and deployment characteristics (for example, encapsulation, internal reflectors, and open versus buried deployment), ambient environmental conditions, and other factors strongly influence blast pressure amplitude (positive and negative), phase duration, impulse history, waveform structure, and target interactions (30, 84-86). (B and C) ICP waveform and impulse profile in the brain of an 
intact living mouse (B) and isolated mouse head severed at the cervical spine (C) subjected to the same blast conditions as in (A). Blast waveforms recorded in the brains of living mice (B) and isolated heads (C) were similar in amplitude to each other and to the measured freefield static pressure. Small differences in the ICP signal waveforms were within the expected range given differences in frequency-dependent transducer response characteristics and experimental preparations. (D) Kinetographic representation of projected Cartesian motion of a representative mouse head during blast exposure as determined by high-speed videography acquired at 100,000 frames per second. Cartesian motion of the head was calculated by tracking a reflective paint mark on the snout. Labeled time points identify corresponding time points in (A) and (E) to (G). (E to G) Relative position (E), angular velocity $(\mathrm{F})$, and angular acceleration $(\mathrm{G})$ of the mouse head referenced to the horizontal (blue) and sagittal (red) planes of motion as determined by analysis of high-speed videographic records obtained during blast exposure. Head acceleration was most significant during the positive phase of the blast shock wave. 

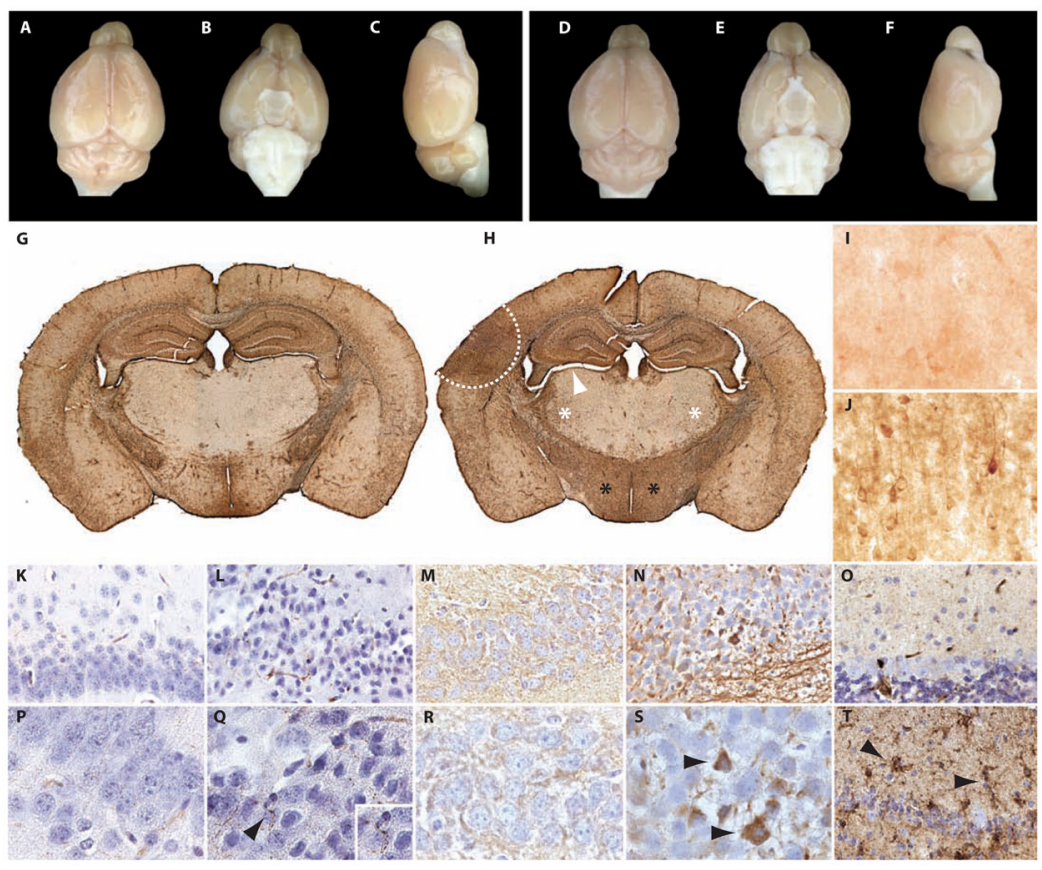

Fig. 3.

Single-blast exposure induces CTE-like neuropathology in wild-type C57BL/6 mice. (A to F) Absence of macroscopic tissue damage (contusion, necrosis, hematoma, or hemorrhage) 1 day (A to C) or 2 weeks ( $D$ to $F$ ) after exposure to a single blast. Experimental blast conditions were compatible with $100 \%$ survival and full recovery of gross locomotor function. (G) Normal astrocytic glial fibrillary acidic protein (GFAP) immunoreactivity in a mouse brain 2 weeks after exposure to sham blast. Whole-mount sections. (H) Increased astrocytic GFAP immunoreactivity in the ipsilateral cortex (area enclosed by white hash line), bilateral thalamus (white asterisks), and bilateral hypothalamus (black asterisks) 2 weeks after single-blast exposure. Parenchymal atrophy with ventricular dilation was also observed (white arrowhead). Whole-mount sections. (I) Background phosphorylated tau (CP-13) immunostaining in superficial layers of the cerebral cortex 2 weeks after exposure to sham blast. (J) Phosphorylated tau (CP-13) immunostaining in superficial layers of the cerebral cortex 2 weeks after exposure to a single blast. Increased accumulation of phosphorylated tau in the brains of blast-exposed mice was confirmed by quantitative immunoblot analysis (Fig. 5). (K and P) Background phosphorylated neurofilament (SMI-31) immunostaining in the hippocampus 2 weeks after exposure to sham blast demonstrating normal-appearing CA1 pyramidal neurons with no detectable axonal pathology. (L and Q) Increased phosphorylated neurofilament (SMI-31) immunostaining in the hippocampus 2 weeks after exposure to single blast demonstrating pyknotic CA1 pyramidal neurons with nuclear smudging and injured axons with beaded, irregular swellings [arrowhead, (Q); enlargement shown in inset]. (M and R) Faint total tau (Tau-46) immunoreactivity in the soma and processes of pyramidal neurons in the hippocampal CA1 field 2 weeks after exposure to sham blast. ( $\mathbf{N}$ and $\mathbf{S}$ ) Increased total tau (Tau-46) immunoreactivity in the soma and processes of pyramidal neurons [arrowheads, $(\mathrm{S})$ ] in the hippocampal CA1 field 2 weeks after exposure to single blast. Biochemical abnormalities in total tau expression in the brains of blast-exposed mice were confirmed by quantitative immunoblot analysis (Fig. 5). (O) Faint activated microglial [Ricinus communis agglutinin (RCA)] immunoreactivity in the cerebellum 2 weeks after exposure to sham blast. (T) Increased activated microglial RCA immunoreactivity in the cerebellum indicative of brisk microgliosis [arrowheads, $(\mathrm{T})] 2$ weeks after exposure to single blast. 

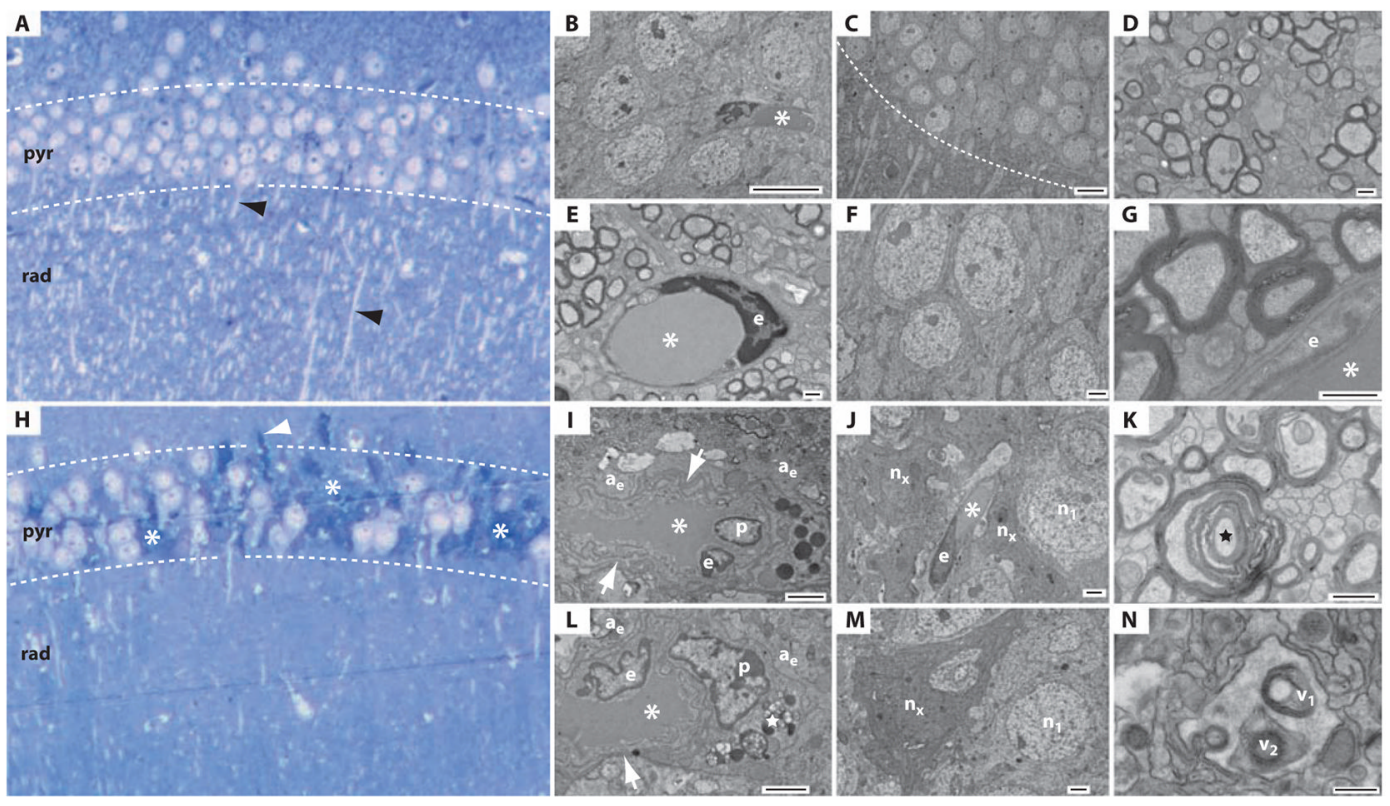

Fig. 4.

Single-blast exposure induces hippocampal ultrastructural pathology in wild-type C57BL/6 mice. (A to G) Normal histology and ultrastructure in the hippocampal CA1 field 2 weeks after sham-blast exposure. (A) Tolui-dine blue-stained semithick section of the hippocampal CA1 field after sham blast. The CA1 field exhibits normal histological structure with a densely compacted layer of intact pyramidal neurons in the stratum pyramidale (pyr) and profuse dendritic profiles (black arrowheads) in the stratum radiatum (rad). (B to G) Electron micrographs of adjacent ultrathin sections demonstrating normal neuronal, axonal, and perivascular ultrastructure in the hippocampal CA1 field 2 weeks after sham-blast exposure. (B) CA1 pyramidal neurons in proximity to a capillary (asterisk) and endothelial cell. Scale bar, $10 \mu \mathrm{m}$. (C) Hippocampal CA1 field with normal stratum pyramidale (above white hash line) and stratum radiatum (below white hash line). Numerous dendrites are evident in the stratum radiatum. Scale bar, $10 \mu \mathrm{m}$. (D) Axon field in the stratum alveus demonstrating normal neuropil ultrastructure. Scale bar, $500 \mathrm{~nm}$. (E) Capillary (asterisk) with endothelial cell nucleus (e) in a field of myelinated axons demonstrating normal ultrastructure in the stratum alveus. Scale bar, $500 \mathrm{~nm}$. (F) Pyramidal neurons with normal ultrastructure in the hippocampal CA1 field. Scale bar, $2 \mu \mathrm{m}$. (G) Myelinated axons in transverse section in proximity to a capillary (asterisk) and endothelial cell (e). Scale bar, $500 \mathrm{~nm}$. (H to $\mathbf{N}$ ) Histological and ultrastructural pathology in the hippocampal CA1 field 2 weeks after single-blast exposure. $(\mathrm{H})$ Toluidine blue-stained semithick section of hippocampus. Clusters of chromatolytic and pyknotic neurons (asterisks) are evident throughout the stratum pyramidale (pyr). Note the marked paucity of dendrites in the stratum radiatum (rad). A tortuous axon (white arrowhead) is present at the boundary between the stratum pyramidale and the stratum oriens. (I to N) Electron micrographs of adjacent ultrathin cryosections demonstrating widespread ultrastructural pathology in the hippocampal CA1 field 2 weeks after single-blast exposure. (I) Hydropic perivascular astrocytic end-feet $\left(\mathrm{a}_{\mathrm{e}}\right)$ surround an abnormal capillary (asterisk) and endothelial cell (e). The astrocytic end-feet are grossly distended and edematous. Numerous vacuoles are scattered throughout the pale cytoplasm. The capillary exhibits an abnormal shape and grossly thickened, tortuous basal lamina (white arrow). A pericyte (p) and numerous electron-dense inclusion bodies are also present. Scale bar, $2 \mu \mathrm{m}$. (J) Degenerating pyramidal neurons $\left(\mathrm{n}_{\mathrm{x}}\right)$ in proximity to a capillary (asterisk), endothelial cell (e), and 
swollen, hydropic processes of a perivascular astrocyte in the stratum pyramidale. A neighboring pyramidal neuron $\left(\mathrm{n}_{1}\right)$ appears normal. Scale bar, $2 \mu \mathrm{m}$. An enlarged field of this same region is shown in fig. S20. (K) Degenerating myelinated nerve fiber (black star) in the stratum alveus. Scale bar, $500 \mathrm{~nm}$. (L) Swollen, hydropic perivascular astrocyte endfeet $\left(\mathrm{a}_{\mathrm{e}}\right)$ surrounding a dysmorphic capillary (asterisk) in the hippocampal CA1 field. Note the abnormal endothelial cell (e) with irregularly shaped nucleus and nearby perivascular pericyte (p). The capillary basal lamina (white arrow) is grossly thickened. Lipofuscin granules (white star) are present in an adjacent process. Scale bar, $500 \mathrm{~nm}$. A micrographic montage (fig. S11; corresponding high-magnification micrographs, fig. S12) of this same region reveals the soma and communicating processes of this perivascular astrocyte. (M) Degenerating CA1 pyramidal neuron $\left(\mathrm{n}_{\mathrm{x}}\right)$ in the stratum pyramidale of the hippocampal CA1 field. The electron-dense cytoplasm and condensed nucleus of this "dark neuron" correspond to the pyknotic neurons observed in toluidine blue-stained semithick sections (Fig. $4 \mathrm{H}$ ). A neighboring neuron $\left(\mathrm{n}_{1}\right)$ appears normal. Scale bar, $2 \mu \mathrm{m}$. (N) Presumptive autophagic vacuoles $\left(\mathrm{v}_{1}, \mathrm{v}_{2}\right)$ in a perivascular astrocyte in the hippocampal CA1 field. Scale bar, $500 \mathrm{~nm}$. 
A

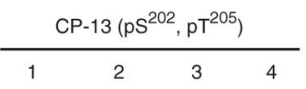

$53 \mathrm{kD}$

$\frac{\text { Left } \quad \text { Right }}{\text { Sham } 11} \frac{\text { Left } \quad \text { Right }}{\text { Sham } 12}$

C

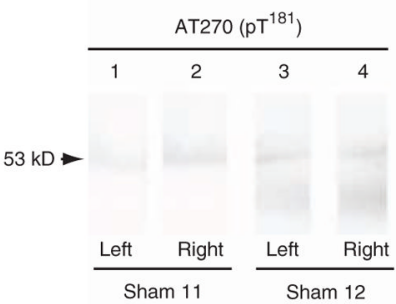

E

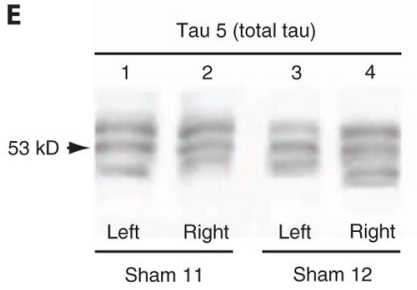

B
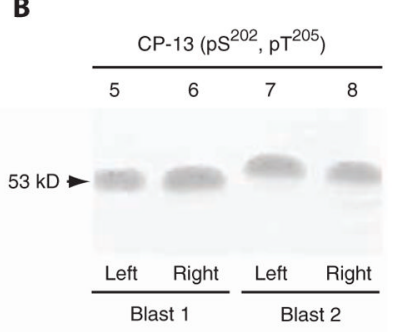

D

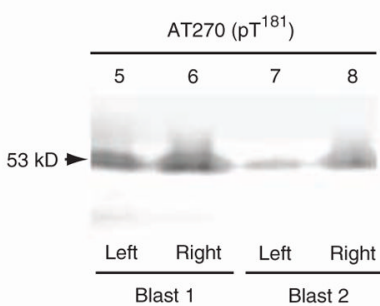

$\mathbf{F}$

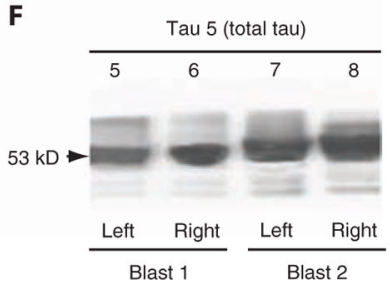

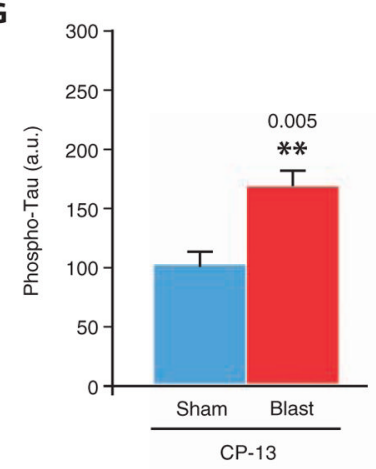

I

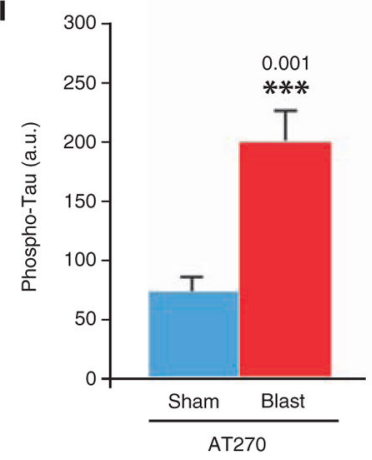

H

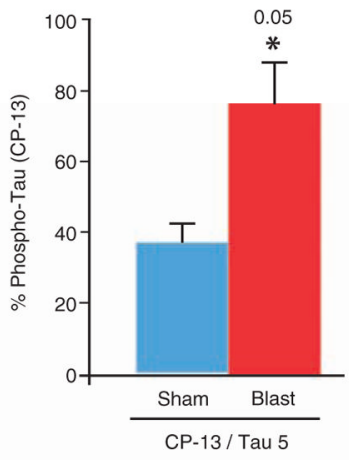

J

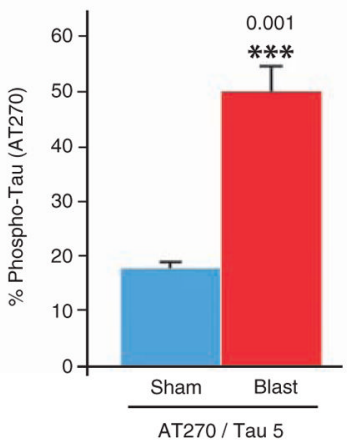

Fig. 5.

Single-blast exposure induces increased brain tau protein phosphorylation in wild-type C57BL/6 mice. (A and $\mathbf{B}$ ) Immunoblots of brain extracts from the left and right hemispheres of mice probed with monoclonal antibody $\mathrm{CP}-13$ directed against phosphorylated tau protein $\left(\mathrm{pS}^{202} / \mathrm{pT}^{205}\right) 2$ weeks after exposure to sham blast (lanes 1 to 4 ) or single blast (lanes 5 to 8). Note the single broad band that migrated with an apparent molecular mass of $53 \mathrm{kD}$ (arrows) in brains from mice in both groups. (C and $\mathbf{D})$ Immunoblots of brain extracts from the left and right hemispheres of mice probed with monoclonal antibody AT270 directed against phosphorylated tau protein $\left(\mathrm{pT}^{181}\right)$ using the same homogenates as in (A) and (B). $(\mathbf{E}$ and $\mathbf{F})$ Immunoblots of brain extracts from the left and right hemispheres of mice probed with monoclonal antibody Tau 5 directed against total tau protein using the same homogenates as in (A) to (D). Unlike the results shown in the preceding panels, Tau 5 immunoblots revealed an apparent blast-related alteration in tau protein isoform distribution. (G) Densitometric quantitation of CP-13 phosphorylated tau protein $\left(\mathrm{pS}^{202} / \mathrm{pT}^{205}\right)$ immunolabel in brain homogenates from mice exposed to single blast or sham blast 2 weeks before euthanizing. Mean values \pm SEM in arbitrary densitometric units (a.u.). $P<0.005$, two-tailed Student's $t$ test. (H) Densitometric quantitation of CP-13 phosphorylated tau protein $\left(\mathrm{pS}^{202} / \mathrm{pT}^{205}\right)$ immunolabel in brain homogenates as a proportion of total tau protein (Tau 5) in brain homogenates from mice exposed to single blast or sham blast 2 weeks before euthanizing. Mean values \pm SEM in arbitrary densitometric units. $P<0.05$, twotailed Student's $t$ test. (I) Densitometric quantitation of AT270 phosphorylated tau protein $\left(\mathrm{pT}^{181}\right)$ immunolabel in brain homogenates from mice exposed to single blast or sham blast 2 weeks before euthanizing. Mean values \pm SEM in arbitrary densitometric units. $P<0.001$, two-tailed Student's $t$ test. (J) Densitometric quantitation of AT270 phosphorylated tau protein $\left(\mathrm{pT}^{181}\right.$ ) immunolabel in brain homogenates as a proportion of total tau protein (Tau 
5) in brain homogenates from mice exposed to single blast or sham blast 2 weeks before euthanizing. Mean values \pm SEM in arbitrary densitometric units. $P<0.001$, two-tailed Student's $t$ test. 
A

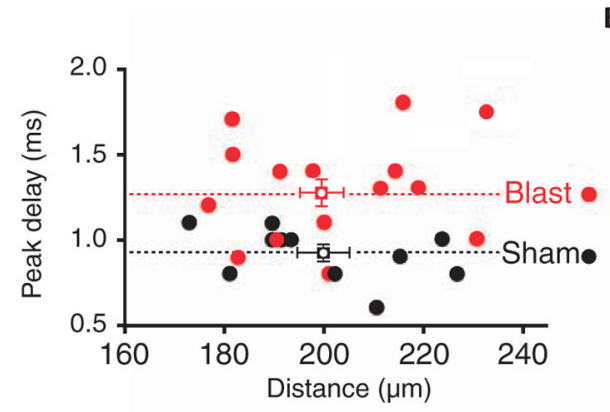

C

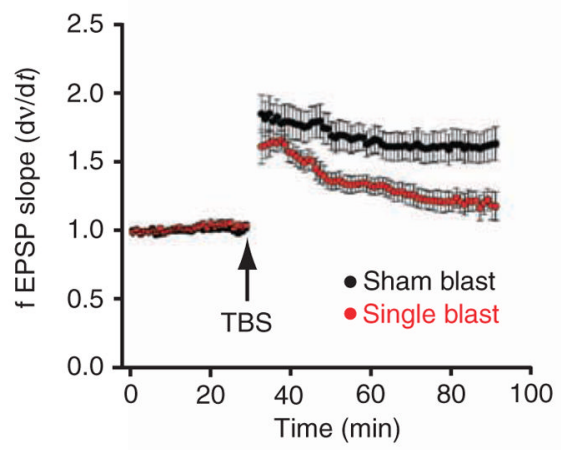

$\mathbf{E}$

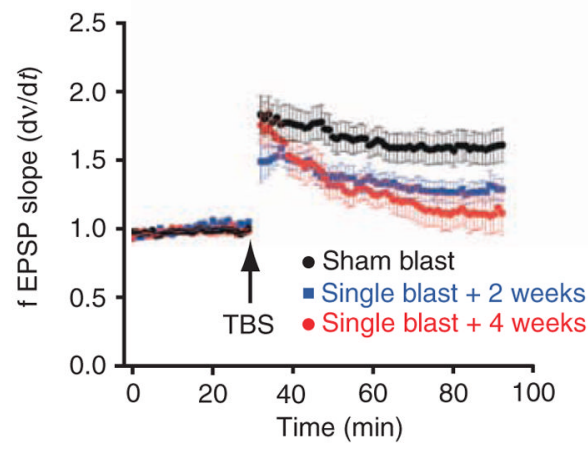

B
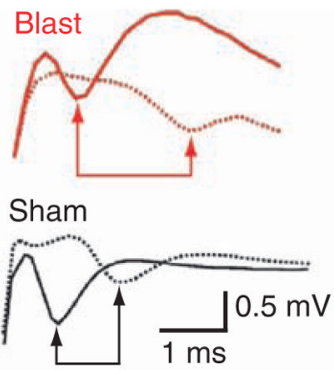

D

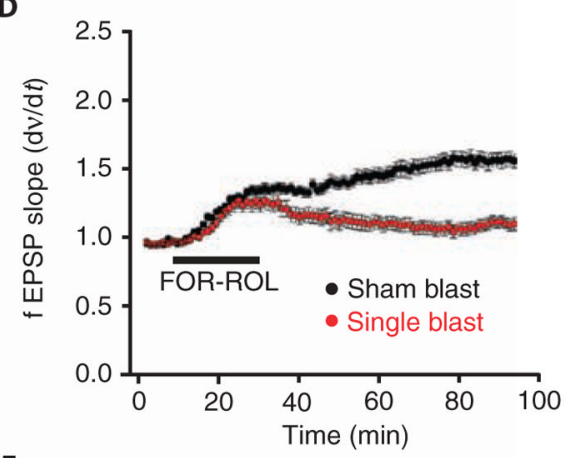

$\mathbf{F}$

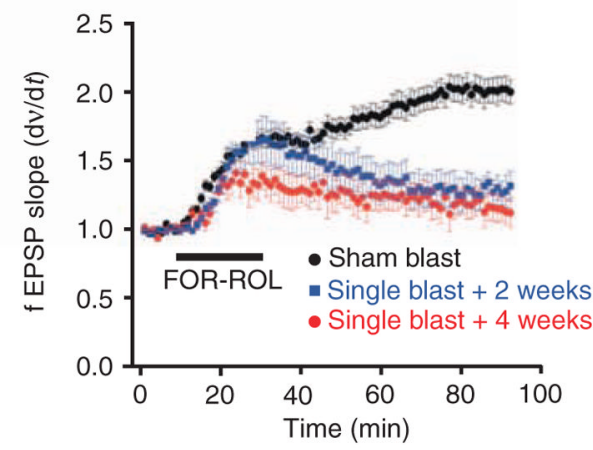

Fig. 6.

Single-blast exposure induces persistent impairments in axonal conduction velocity and LTP of synaptic transmission in wild-type C57BL/6 mice. (A) Conduction velocity measurements of first peak compound action potential delay as a function of distance between recording electrodes in CA1 pyramidal cell axons in the stratum alveus of hippocampal slices from mice exposed to single blast (red circles, $n=13$ ) compared to sham blast (black circles, $n=11$ ). Mean \pm SEM for each group. (B) Representative stimulusevoked compound action potentials at proximal and distal recording sites (solid and hash lines, respectively) in hippocampal slices from mice exposed to single blast (red) and sham blast (black). Arrows indicate peak negativities used to calculate conduction velocity. (C) Time course of LTP at Schaffer collateral-CA1 synapses evoked by TBS in hippocampal slices from mice exposed to single blast (red circles, $n=17$ ) compared to sham blast (black circles, $n=11$ ). Each point mean \pm SEM fEPSP slope of $n$ slices. (D) Time course of LTP at Schaffer collateral-CA1 synapses evoked by bath application of the adenylate cyclase stimulant forskolin $(50 \mu \mathrm{M})$ plus the type II phosphodiesterase inhibitor rolipram $(10 \mu \mathrm{M}$; bar, FOR+ROL) in hippocampal slices from mice exposed to single blast (red circles, $n=$ 27) compared to sham blast (black circles, $n=19$ ). Each point mean \pm SEM fEPSP slope of $n$ slices. (E) Time course of LTP at Schaffer collateral-CA1 synapses evoked by TBS in hippocampal slices from mice 2 weeks (blue squares, $n=10$ ) and 4 weeks after exposure to 
single blast (red circles, $n=7$ ) compared to each other and to sham blast (black circles, $n=$ 11). Each point mean \pm SEM fEPSP slope of $n$ slices. (F) Time course of long-lasting potentiation at Schaffer collateral-CA1 synapses evoked by bath application of the adenylate cyclase stimulant forskolin $(50 \mu \mathrm{M})$ plus the type II phosphodiesterase inhibitor rolipram $(10 \mu \mathrm{M}$; bar, FOR+ROL) in hippocampal slices from mice 2 weeks (squares, $n=$ 12) and 4 weeks after exposure to single blast (red circles, $n=15$ ) compared to each other and to sham blast (black circles, $n=19$ ). Each point mean \pm SEM fEPSP slope of $n$ slices. 


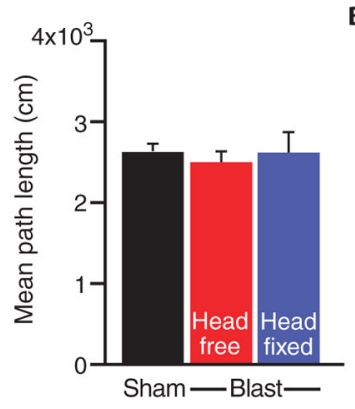

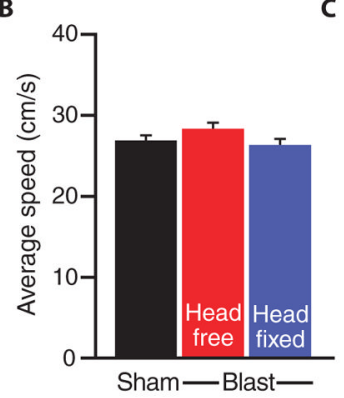

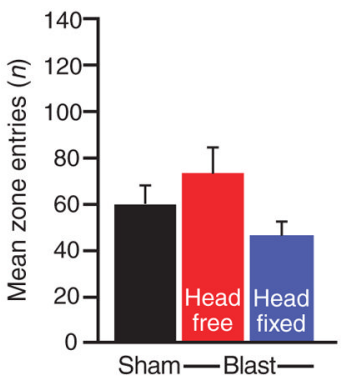

D

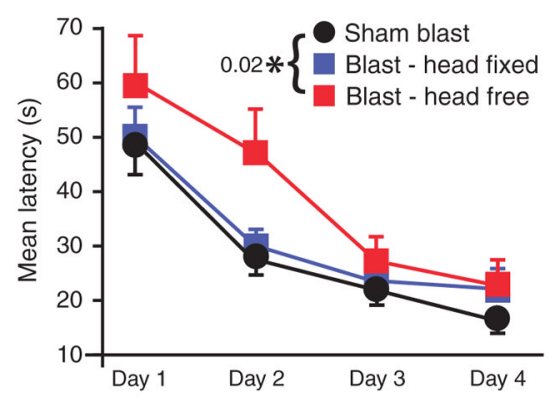

F

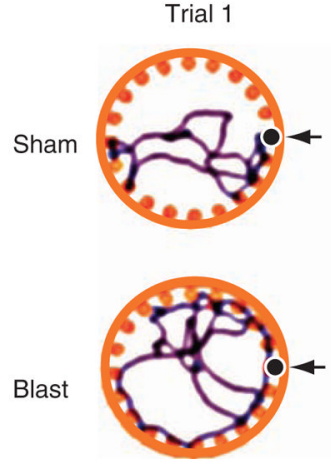

E

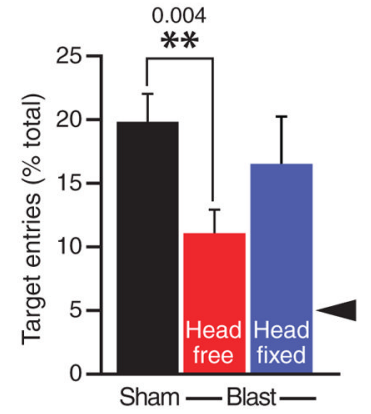

Trial 16
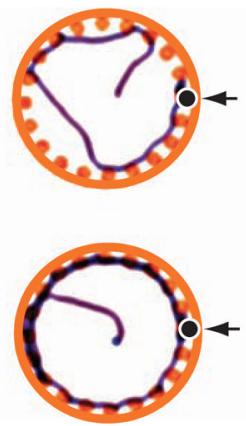
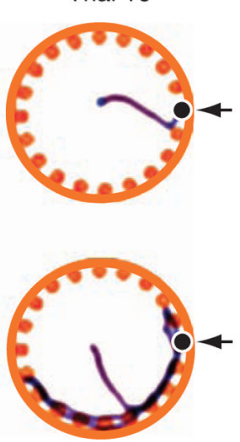

Fig. 7.

Single-blast exposure in wild-type C57BL/6 mice induces persistent hippocampal-dependent learning and memory deficits that are prevented by head fixation (immobilization) during blast exposure. (A to $\mathbf{C}$ ) Open-field testing showed no effect of blast exposure on gross locomotor function, explorative activity, or thigmotaxis as measured by total distance traveled (A), mean velocity (B), and number of central zone entries (C), respectively, in mice exposed to single blast (red bars, single blast, head free, $n=10$; blue bars, single blast, head fixed, $n=10$ ) or sham blast (black bars, sham blast, $n=20$ ). (D to F) Barnes maze testing demonstrated significant impairments in hippocampal-dependent spatial learning acquisition measured by decreasing latency to find the escape box across 4 days of training (D) (two-way ANOVA, $P=0.020$ ) and long-term memory assessed by escape box location recall assessed 24 hours after the last training session $(\mathrm{E})(* * P=0.004$, Student's $t$ test). Mice exposed to single blast (red squares, single blast, head free, $n=10$ ) are compared to pooled sham-blast control mice (circles, sham blast, $n=20$ ). Fixation (immobilization) of the head during blast exposure (blue squares, single blast, head fixed, $n=10$ ) reversed blastinduced learning and memory deficits. Arrowhead in (E) represents 5\% level predicted by chance selection of the escape box from among the 20-hole choices. (F) Representative 
Barnes maze tracks obtained on trials 1, 8, and 16 for mice exposed to a single blast (bottom row) compared to sham blast (top row). 